\title{
Assessment of Dissolved Oxygen Mitigation at Hydropower Dams Using an Integrated Hydrodynamic/Water Quality/Fish Growth Model
}

MARCH 2006

Prepared by Mark S. Bevelhimer Charles C. Coutant 


\section{DOCUMENT AVAILABILITY}

Reports produced after January 1,1996, are generally available free via the U.S. Department of Energy (DOE) Information Bridge.

Web site http://www.osti.gov/bridge

Reports produced before January 1, 1996, may be purchased by members of the public from the following source.

National Technical Information Service

5285 Port Royal Road

Springfield, VA 22161

Telephone 703-605-6000 (1-800-553-6847)

TDD 703-487-4639

Fax 703-605-6900

E-mail info@ntis.fedworld.gov

Web site $\mathrm{http}: / /$ www.ntis.gov/support/ordernowabout.htm

Reports are available to DOE employees, DOE contractors, Energy Technology Data Exchange (ETDE) representatives, and International Nuclear Information System (INIS) representatives from the following source.

Office of Scientific and Technical Information

P.O. Box 62

Oak Ridge, TN 37831

Telephone 865-576-8401

Fax 865-576-5728

E-mail reports@adonis.osti.gov

Web site http://www.osti.gov/contact.html

This report was prepared as an account of work sponsored by an agency of the United States Government. Neither the United States Government nor any agency thereof, nor any of their employees, makes any warranty, express or implied, or assumes any legal liability or responsibility for the accuracy, completeness, or usefulness of any information, apparatus, product, or process disclosed, or represents that its use would not infringe privately owned rights. Reference herein to any specific commercial product, process, or service by trade name, trademark, manufacturer, or otherwise, does not necessarily constitute or imply its endorsement, recommendation, or favoring by the United States Government or any agency thereof. The views and opinions of authors expressed herein do not necessarily state or reflect those of the United States Government or any agency thereof. 
Environmental Sciences Division

\title{
ASSESSMENT OF DISSOLVED OXYGEN MITIGATION AT HYDROPOWER DAMS USING AN INTEGRATED HYDRODYNAMIC/WATER QUALITY/FISH GROWTH MODEL
}

\author{
M. S. Bevelhimer \\ C. C. Coutant \\ Environmental Sciences Division \\ Oak Ridge National Laboratory
}

Date Published: March 2006

\author{
Prepared for \\ U. S. Department of Energy \\ Office of Energy Efficiency and Renewable Energy \\ Wind and Hydropower Technologies
}

\author{
Prepared by \\ OAK RIDGE NATIONAL LABORATORY \\ Oak Ridge, Tennessee 37831-6335 \\ managed by \\ UT-BATTELLE, LLC \\ for the \\ U.S. DEPARTMENT OF ENERGY \\ under contract DE-AC05-00OR22725
}




\section{CONTENTS}

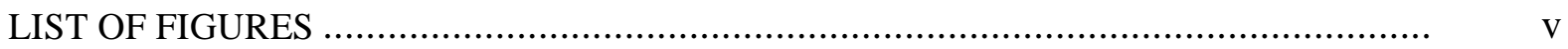

ACKNOWLEDGEMENTS ................................................................................. vii

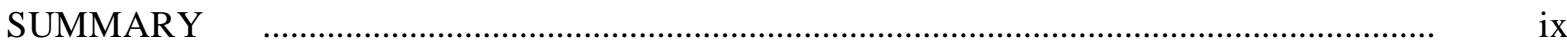

INTRODUCTION

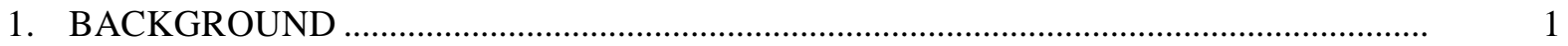

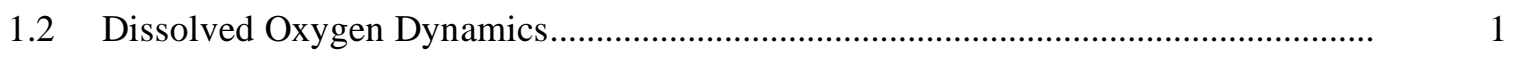

1.3 DEEP RELEASES AT HYDROPOWER DAMS ........................................... 3

1.4 EFFECTS OF LOW DISSOLVED OXYGEN ON AQUATIC LIFE .................... 4

1.5 MITIGATION MEASURES ..................................................................... 4

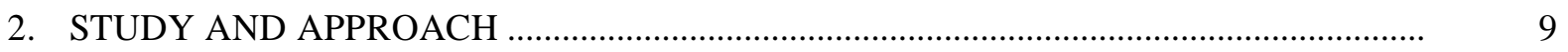

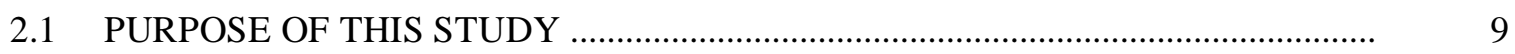

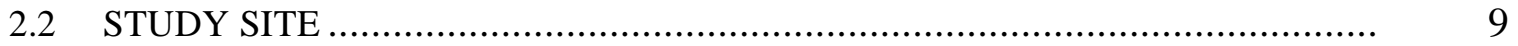

2.3 MODEL DESCRIPTION ................................................................... 12

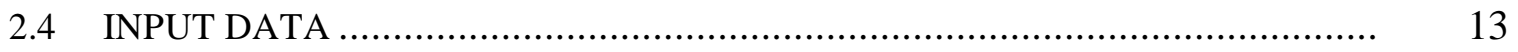

2.4.1 Hydrodynamic Model Data Requirements ....................................................... 14

2.4.2 Water Quality Model Data Requirements ....................................................... 18

2.4.3 Fish Growth Model Data Requirements ............................................................. 21

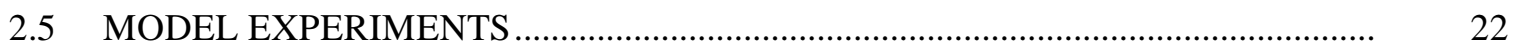

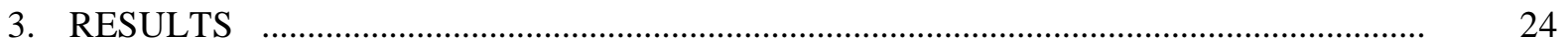

3.1 MODEL CALIBRATION AND BASELINE SIMULATION ...................................... 24

3.1.1 Water Quantity and Quality .................................................................................. 24

3.1.2 Fish Growth ................................................................................................ 28

3.2 MITIGATION SIMULATED BENEFITS OF TURBINE AERATION ..................... 30

3.2.1 Water Quality .......................................................................................... 31

3.2.2 Fish Growth ......................................................................................... $\quad 34$

3.3 SIMULATED BENEFITS OF FOREBAY AERATION ........................................... 36

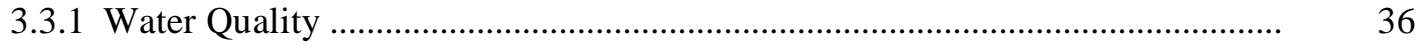

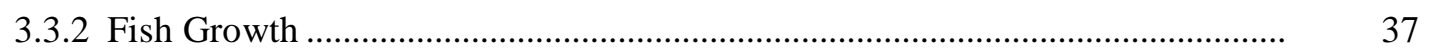

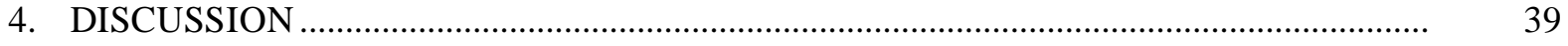

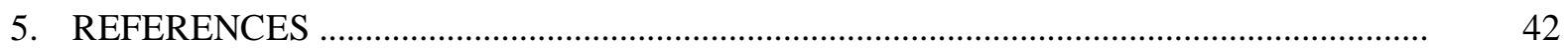





\section{LIST OF FIGURES}

Figure $\quad$ Page

1.1 Typical seasonal thermal mixing and stratification that leads to low dissolved oxygen in lakes and reservoirs.

2.1 Weight of 286 individual brown trout captured in Caney Fork River from April 2003 through April 2004.

2.2 Average brown trout weight for three river reaches: Below Dam (RM 24.5-26.5), Upper (RM 19.5-26.5), and Lower (RM 12.5-19.5).

2.3 Map of the Caney Fork River below Center Hill Dam. The dam is at the lower right and the confluence with the Cumberland River is at the upper left

2.4 Hourly flow from Center Hill Dam, which shows periods when one (approx. $3,500 \mathrm{cfs}$ ), two (approx. 7,000 cfs), or three (approx. 10,500 cfs) turbines are operating intermittently between periods of no flow

2.5 A finer temporal scale view of flow from the Center Hill Dam illustrating the daily peaking operation of the project.

2.6 Daily flow at Smith Fork Creek, the largest tributary to the Caney Fork River downstream of the dam, which illustrates the difference between natural flow dynamics for the region and those below the dam.

2.7 Flow duration curves for Smith Fork Creek and Center Hill Dam release for the period 1 March 2003 to 30 April 2004.

2.8 Daily minimum temperature in the tailrace of Center Hill Dam which was used to represent the temperature of the dam discharge

2.9 Fitted relationship (5th order polynomial) between water temperature and Julian day for data collected since 1991 from Smith Fork Creek.

2.10 Polynomial relationship between day of year and dissolved oxygen derived from twelve years of grab samples below the Center Hill Dam

2.11 Relationships between food consumption, growth, and respiration for brown trout in the fish growth model based on equations and parameters used in the model

2.12 Relationship between ambient DO and the appetite mulitplier used to restrict food consumption at low DO.

2.13 Example of dam release DO levels for simulated improvement to $5 \mathrm{mg} / \mathrm{L}$ compared to the baseline. 


\section{LIST OF FIGURES (continued)}

3.1 Model generated temporal profile of hourly temperature for three reaches below Center Hill Dam under baseline conditions.

3.2 Model generated temporal profile of hourly dissolved oxygen for three reaches below Center Hill Dam under baseline conditions.

3.3 Maximum, mean, and minimum dissolved oxygen over the entire 26.5 mile tailwater during five 10-day periods....

3.4 Calibrated model predictions of brown trout weight during the course of the simulation for three river reaches (lines) compared to observed weights of individual trout (diamonds)

3.5 Model prediction of brown trout growth in the Upper reach compared to observed weights from fish captured from sample sites in the same reach....

3.6 Model prediction of brown trout growth in the Lower reach compared to observed weights from fish captured from sample sites in the same reach

3.7 Model simulated growth of trout in three reaches below Center Hill Dam with DO effects turned off.

3.8 Model-simulated hourly DO at three locations in the Caney Fork River when dam release limited to a minimum DO of $5 \mathrm{mg} / \mathrm{L}$.

3.9 Maximum (dashed), mean (solid), and minimum (dotted) dissolved oxygen levels in the Caney Fork River for three periods during a simulated mitigation (red lines) that improved DO in dam releases to $4 \mathrm{mg} / \mathrm{L}$

3.10 Maximum (dashed), mean (solid), and minimum (dotted) dissolved oxygen levels in the Caney Fork River for three periods during a simulated mitigation (red lines) that improved DO in dam releases to $6 \mathrm{mg} / \mathrm{L}$

3.11 Simulated trout growth under conditions of incremental improvements in DO at three reaches of the Caney Fork River below Center Hill Dam.

3.12 Maximum (dashed), mean (solid), and minimum (dotted) temperatures in the Caney Fork River for three periods during a simulated mitigation (red lines) that improved DO in dam releases to $5 \mathrm{mg} / \mathrm{L}$, but also increased temperature by $3^{\circ} \mathrm{C}$

3.13 Simulated trout growth under conditions of increased DO and increased temperature at three reaches of the Caney Fork River below Center Hill Dam as might be expected from mixing surface waters to increase DO. 


\section{ACKNOWLEDGEMENTS}

We thank Robert Sneed with the USACE Nashville District for providing flow and water quality data for Center Hill dam for 2003-2004, Phil Bettoli and Jonathan Meerbeek of Tennessee Technological University for providing trout growth and water quality data for the Caney Fork River, and Gary Hauser for providing the most recent version of the ADYN/RQUAL/FISH model. Glenn Cada and Brennan Smith provided useful comments on earlier versions of the report. This research was funded by the U.S. Department of Energy Office of Energy Efficiency and Renewable Energy Wind and Hydropower Technologies Program. 



\section{SUMMARY}

Dissolved oxygen (DO) in rivers is a common environmental problem associated with hydropower projects. Approximately $40 \%$ of all FERC-licensed projects have requirements to monitor and/or mitigate downstream DO conditions. Most forms of mitigation for increasing DO in dam tailwaters are fairly expensive. One area of research of the Department of Energy's Hydropower Program is the development of advanced turbines that improve downstream water quality and have other environmental benefits. There is great interest in being able to predict the benefits of these modifications prior to committing to the cost of new equipment. In the case of turbine replacement or modification, there is a need for methods that allow us to accurately extrapolate the benefits derived from one or two turbines with better design to the replacement or modification of all turbines at a site.

The main objective of our study was to demonstrate a modeling approach that integrates the effects of flow and water quality dynamics with fish bioenergetics to predict DO mitigation effectiveness over long river segments downstream of hydropower dams. We were particularly interested in demonstrating the incremental value of including a fish growth model as a measure of biological response. The models applied are a suite of tools (RMS4 modeling system) originally developed by the Tennessee Valley Authority for simulating hydrodynamics (ADYN model), water quality (RQUAL model), and fish growth (FISH model) as influenced by DO, temperature, and available food base.

We parameterized a model for a 26-mile reach of the Caney Fork River (Tennessee) below Center Hill Dam to assess how improvements in DO at the dam discharge would affect water quality and fish growth throughout the river. We simulated different types of mitigation (i.e., at the turbine and in the reservoir forebay) and different levels of improvement. The model application successfully demonstrates how a modeling approach like this one can be used to assess whether a prescribed mitigation is likely to meet intended objectives from both a water quality and a biological resource perspective. These techniques can be used to assess the tradeoffs between hydropower operations, power generation, and environmental quality. 



\section{INTRODUCTION}

\subsection{BACKGROUND}

The release of water with low dissolved oxygen content in summer is one of the environmental changes often associated with hydropower dam (Sale et al. 1991, EPRI 1992). Dissolved oxygen is necessary for aquatic life, generally at concentrations above about $5 \mathrm{mg} / \mathrm{L}$, which is a common state water quality standard for surface waters. This standard may not be met in dam tailwaters and for considerable distance downstream, with resulting regulatory pressures to meet standards. Dam discharges also can contain dissolved and suspended organic matter that exert a biological or chemical oxygen demand as it decomposes, causing further depletion of dissolved oxygen in downstream rivers.

Dam tailwaters also can be cold in summer, even in warm climates. Cold reservoir releases often provide suitable thermal habitat for trout, which have more exacting requirements for dissolved oxygen than temperate riverine fauna in general. Thus, there is usually strong angler pressure through state fish and wildlife agencies for dam tailwaters to contain sufficient dissolved oxygen for a coldwater trout fishery.

In the 1980s, there was a well-publicized court case (National Wildlife Federation v. Gorsuch D.C. Circuit Court of Appeals 1982) in which the plaintiff requested that a dam be classified as a point source discharger under the Clean Water Act, similar to a sewage outfall, and thus should be regulated accordingly. The main concern was low dissolved oxygen and oxygen-reducing organic loading. This classification would have required dam operators to apply for discharge permits under the National Pollutant Discharge Elimination System or its delegated state equivalent. Although this designation was denied, there was much attention drawn to the issue of low dissolved oxygen below hydropower dams.

In a review of approximately 300 project records for hydropower dams regulated by the Federal Energy Regulatory Commission (FERC) since 1986, 40.2\% have a specific requirement for dissolved oxygen in the tailwater (EPRI 1992). A common requirement (37.2\%) was for monitoring of dissolved oxygen, while mitigation measures (38.2\%) and/or changes in project operation $(35.2 \%)$ were often required. Models are beginning to be used to provide additional insight into water quality dynamics, with $2 \%$ of the records requiring monitoring specifically to verify models.

\subsection{DISSOLVED OXYGEN DYNAMICS}

Dam discharges can have low dissolved oxygen because of the ecological dynamics of their reservoirs, not because of the dam itself. This was the crucial point in resolving the court case over the Clean Water Act in favor of dam operators. Nonetheless, the combined dam-reservoir system acts to create the low dissolved oxygen concentrations and then to release this low-oxygen water through turbines to the downstream river. To understand the origin of the depleted oxygen, one must understand the basic seasonal functioning of a lake or reservoir.

Any lake or reservoir in the temperate zone responds to an annual cycle of heating and cooling. Solar radiation provides varying levels of direct heating to the water surface, inflowing streams tend to follow the annual pattern of air temperatures, and the lake or reservoir itself is influenced by the air temperature of winds blowing on it. The annual heat balance, which is capable of being modeled in some detail, results in the typical pattern of cold water in winter, spring heating, and autumn cooling. Because water of different temperature has different densities, static water bodies undergo an annual pattern of changing water density. Water's maximum density is $4^{\circ} \mathrm{C}$. In winter, the water body is often uniformly mixed (Fig. 1.1 - top panel) (or with a layer of ice and very cold water at the 

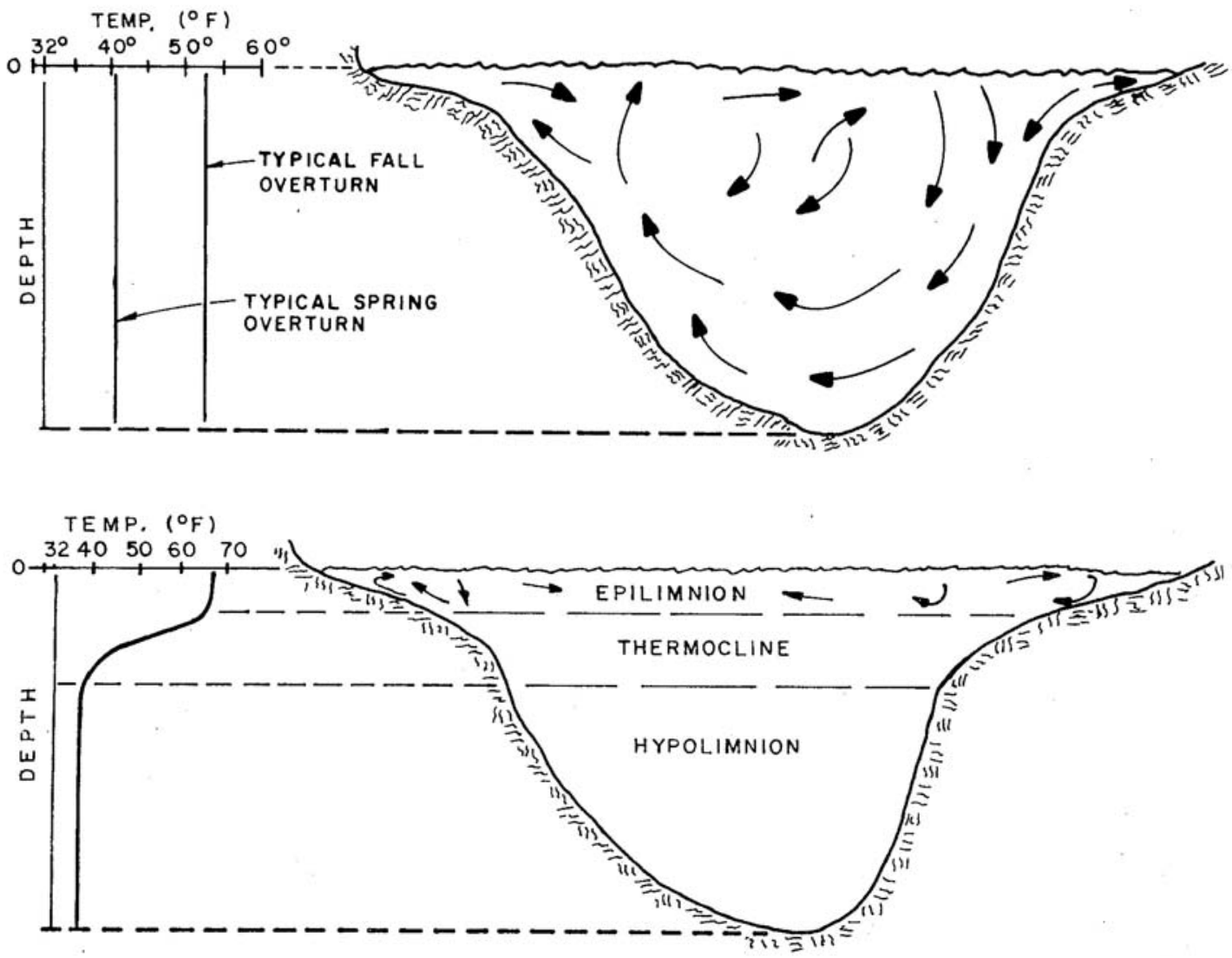

Fig. 1.1 Typical seasonal thermal mixing and stratification that leads to low dissolved oxygen in lakes and reservoirs. Top panel represents well-mixed conditions from fall to spring after fall turnover. Bottom panel represents thermally stratified conditions typical in summer and early fall with low dissolved oxygen in the deep hypolimnion. Vertical temperature profile is indicated at the left of each panel.

surface). In spring, heating and river inflows warm the surface but this warmer, less dense water does not mix well with the deeper, cold, and more dense water. Gradually, there is sufficient density difference between the warm surface and the cold bottom that a stable thermal stratification develops (Fig. 1.1- bottom panel). The lake or reservoir essentially becomes two separate bodies of water, a surface layer of warm water well mixed by winds (termed the epilimnion) and a deep layer that is cold and generally isolated from further mixing (hypolimnion). The intermediate layer, or thermocline, is where the most rapid changes in temperature and density with depth occur (see graph at left of Fig. 1.1- bottom panel). Occasionally, a river enters a lake or reservoir at temperatures intermediate between the warm and cold masses, and this water spreads out at intermediate depths matching its temperature, called an interflow.

Dissolved oxygen in the surface layer is maintained near saturation (the maximum amount that can be dissolved at the particular temperature) by several forces. Oxygen diffuses between the air and water in a process that is enhanced by wave action and the wind that constantly refreshes the exposed surface. Phytoplankton and other aquatic plants growing in the lighted surface waters produce oxygen in photosynthesis. Inflowing stream or river water is usually well oxygenated. The physical and biological oxygen replenishment usually is ample to counteract the oxygen demands of living animals and microbial decomposition of detritus in the surface waters. 
The isolated, deep water has no such oxygen-replenishing capability. It is usually deeper than light can penetrate, so no photosynthesis occurs. Organic matter rains down from above, adding an organic load that uses oxygen as it is decomposed by bacteria. As the season progresses from spring into summer, the initial oxygen content is progressively depleted. Even the occasional interflows often bring more decomposable organic matter than oxygen replenishment (in fact, they can bring in large quantities of aquatic or terrestrial plant material, especially during floods). In the near absence (hypoxia) or complete absence (anoxia) of oxygen, chemical reactions take place that reduce dissolved iron and manganese, increase the dissolution of phosphates from the sediments, and convert sulfates to hydrogen sulfide, all of which are detrimental to survival of higher aquatic life. Highly productive lakes and reservoirs, that is, those with high nutrient levels and much biological activity, develop the most severe hypoxia and anoxia.

In a natural lake, the sequence of events in the deep-water hypolimnion is of little practical consequence for most human activities. Beyond swimmers or divers who enjoy sinking into the deeper, cooler water, people rarely notice the stratification. Some water users capitalize on the cooler water, such as for thermoelectric power station cooling or municipal drinking water.

In autumn, the surface waters cool. They eventually cool enough that the densities of the upper and lower layers are not sufficiently different to support a stable stratification. At that time, winds are capable of mixing the entire water column, and the lake becomes uniformly cool again (fall turnover; Fig. 1.1- top panel). If the hypolimnion had been large and very low in dissolved oxygen, the entire mixed lake or reservoir can become low in dissolved oxygen for the short period of fall turnover until re-aeration and mixing can replenish oxygen content.

In northern lakes and reservoirs, ice cover in winter can close off the water surface to oxygen exchange. In extreme cases dissolved oxygen in the whole water body can be depleted over a long period of ice cover in a manner similar to the hypolimnion in summer.

\subsection{DEEP RELEASES AT HYDROPOWER DAMS}

Turbine intakes are typically set deep on the upstream side of the dam primarily to minimize the potential for cavitation at the runner by avoiding excessive suction pressure below the runner. Because of the location of the turbine intake, tailwater oxygen concentrations usually reflect the deepwater source in the reservoir. During autumn, winter and spring periods when the reservoir is well mixed or in early summer when oxygen levels in the hypolimnion are still fairly high, the tailwaters are cold and fairly well oxygenated. As summer advances and the hypolimnion becomes deoxygenated, the released water contains progressively less dissolved oxygen, to the point of having essentially no dissolved oxygen below dams with highly productive reservoirs. A conventional hydropower turbine exerts no influence on the dissolved oxygen concentration of the water that passes through it. That is, it neither adds nor removes oxygen, but transfers water from the reservoir to the river below the dam. Some re-aeration may occur in the turbulent zone of the immediate tailrace, but the low oxygen levels tend to prevail for many miles downstream.

Oxygen irregularities may occur in the tailwaters in late summer and fall. As hydropower production continues to tap the deep, cold water and inflows replenish the upper, warm water, the deeper water mass becomes smaller and may become depleted. The thermocline drops in elevation during this process. Warm, oxygenated water may suddenly become withdrawn by turbine flows as the ever-larger epilimnion (upper water mass) comes to occupy the level of the intakes and above. This depletion of the hypolimnion explains why there may be sudden increases in dissolved oxygen and temperature in hydropower releases in late summer and early fall. Conversely, there may be temporary fall dips in dissolved oxygen reflecting the mixing of anoxic waters below the intakes during fall turnover. 


\subsection{EFFECTS OF LOW DISSOLVED OXYGEN ON AQUATIC LIFE}

Oxygen requirements of aquatic animals, especially fish, have been studied extensively and criteria documents have been prepared by the federal Environmental Protection Agency (EPA 1986) and the water quality control agencies of many states. Different levels of protection are often applied to different habitats - stream organisms accustomed to high dissolved oxygen levels usually require more oxygen than organisms adapted to more static (and often less-well-oxygenated) conditions. Also, dissolved oxygen extremes (minima) are often more important for survival of aquatic life than an average (such as daily) value. Most organisms can tolerate dissolved oxygen levels as low as $2 \mathrm{mg} / \mathrm{L}$ for short periods. But repeated or prolonged exposure to such low levels has detrimental effects on activity, feeding, growth rates, and other normal biological functions. For example, the growth of young fish is slowed markedly if the oxygen concentration falls to $3 \mathrm{mg} / \mathrm{L}$ for part of the day, even if it rises to $100 \%$ saturation at other times.

Because the solubility of oxygen in water changes with temperature (more soluble at low temperatures), assigning an absolute concentration as a standard is sometimes problematic. For this reason, some dissolved oxygen standards based on responses of aquatic organisms are stated in terms of percentage saturation. The ideal situation for most aquatic life would be to have the oxygen content match the saturation value at the prevailing temperature. Cold-water streams in summer typically have saturated values near $11-12 \mathrm{mg} / \mathrm{L}$; warm-water streams or lakes have saturated values near 8-9 mg/L, depending on the exact temperature. Nonetheless, most standards are in the 4-5 mg/L range, corresponding to $50-60 \%$ saturation if the temperature is $25^{\circ} \mathrm{C}$. Debate continues whether such limits are adequate for protection of all aquatic life. Some researchers believe that any diminution of dissolved oxygen below saturation for that temperature is incrementally detrimental. Others profess the existence of species-specific dissolved oxygen thresholds above which biological functions are normal and below which functions deteriorate markedly (Brett 1979).

Despite these on-going debates, the oxygen concentrations downstream of hydroelectric dams are often clearly in the danger zone. Attaining minimum levels of $4-5 \mathrm{mg} / \mathrm{L}$ at the dam release when the water source in the reservoir is essentially zero is a challenge. That challenge has been met by a variety of engineering solutions.

\subsection{MITIGATION MEASURES}

Technologies and operational practices to improve dissolved oxygen in dam tailwaters are being pursued with vigor. Reviews by the U.S. Department of Energy (Sale et al. 1991) and EPRI (2002) identified several and provided summaries of the advantages and disadvantages of each. Examples of the performance of these mitigation measures are given in Tables 1 and 2.

Tailrace weirs are low-head structures built in a zigzag or infuser fashion in tailwaters so that the dam discharge is subjected to a waterfall and plunge pool where dissolution of oxygen in the air is facilitated. They can be quite effective, but have a high capital cost. Side-stream aeration is another technique for aerating water after it has been discharged from the dam. Pumps are typically used to carry water to small pools from where the water cascades down specially designed waterfalls back to the river.

Turbine venting increases DO concentrations in the discharge by entraining air into a turbine where internal turbulence mixes air bubbles into the water. This technique requires small design changes to existing turbines and is one of the less costly methods for increasing discharge DO. In some cases, blowers are used to increase the rate at which air is forced into the turbines. The resulting increase in DO depends on several factors such as the initial DO concentration, temperature, turbine 
Table 1. Examples of oxygenation of dam tailwaters by several techniques. Results shown are about the best consistently attained; results varied seasonally and with plant operations. Adapted from EPRI 2002.

\begin{tabular}{|c|c|c|c|c|c|}
\hline \multirow[b]{2}{*}{ Technique } & \multicolumn{3}{|c|}{ DO Improvement (mg/L) } & \multicolumn{2}{|l|}{ Case Study } \\
\hline & Total & From & To & Dam & Citation \\
\hline \multicolumn{6}{|c|}{ Forebay Mitigation } \\
\hline $\begin{array}{l}\text { Hypolimnion } \\
\text { aeration }\end{array}$ & 4 to 5 & 1 & 6 & $\begin{array}{l}\text { Richard B. Russell Dam, Savannah } \\
\text { R., GA/SC (Corps of Engineers) }\end{array}$ & $\begin{array}{l}\text { Lemons et al. } \\
1998\end{array}$ \\
\hline \multirow{3}{*}{$\begin{array}{l}\text { Surface water } \\
\text { pump }\end{array}$} & 2.3 & 1.3 & 3.6 & $\begin{array}{l}\text { Bagnell Dam, Lake of the Ozarks, } \\
\text { MO (Union Electric Co.) }\end{array}$ & $\begin{array}{l}\text { Garton and } \\
\text { Miller } 1982\end{array}$ \\
\hline & 1.3 & 2.7 & 4.0 & $\begin{array}{l}\text { J. Percy Priest Dam, Stones R., TN } \\
\text { (Corps of Engineers) }\end{array}$ & Price 1988 \\
\hline & 2.0 & 0.1 & 1.2 & $\begin{array}{l}\text { Douglas Dam, Holston R., TN } \\
\text { (TVA) }\end{array}$ & $\begin{array}{l}\text { Mobly et al. } \\
1995\end{array}$ \\
\hline \multicolumn{6}{|c|}{ Turbine Vicinity Mitigation } \\
\hline $\begin{array}{l}\text { Penstock air } \\
\text { injection }\end{array}$ & Up to 5 & 1 & $4-6$ & Tim's Ford Dam, Elk R., TN (TVA) & $\begin{array}{l}\text { Harshbarger } \\
\text { et al. } 1995\end{array}$ \\
\hline Draft tube venting & 0.5 to $>3$ & 4 & 6 & $\begin{array}{l}\text { Logan Martin Dam, Coosa R., AL } \\
\text { (Alabama Power Co.) }\end{array}$ & EPRI 2002 \\
\hline $\begin{array}{l}\text { Turbine venting } \\
\text { (vacuum breaker) }\end{array}$ & Up to 3.5 & & & $\begin{array}{l}\text { Deer Cr. Power Plant, Provo R., UT } \\
\text { (Bureau of Reclamation) }\end{array}$ & $\begin{array}{l}\text { Wahl et al. } \\
1994\end{array}$ \\
\hline \multirow{3}{*}{$\begin{array}{l}\text { Turbine venting } \\
\text { (baffles) }\end{array}$} & $\begin{array}{c}2 \text { to } 3 \\
\text { (single } \\
\text { unit); } 1-2 \\
\text { ( } 8 \text { units) }\end{array}$ & & & $\begin{array}{l}\text { Bulls Shoals Dam, White R., AR } \\
\text { (Southwestern Power Admin.) }\end{array}$ & $\begin{array}{l}\text { Harshbarger } \\
\text { et al. } 1998\end{array}$ \\
\hline & 2 to 3 & & & $\begin{array}{l}\text { Table Rock Dam, White R., AR } \\
\text { (Southwestern Power Admin.) }\end{array}$ & $\begin{array}{l}\text { Harshbarger } \\
\text { et al. } 1998\end{array}$ \\
\hline & $\begin{array}{c}2.5 \text { to } 3 \\
\text { (one unit); } \\
0.5(2 \\
\text { units) }\end{array}$ & & & $\begin{array}{l}\text { Norfolk Dam, White R., AR } \\
\text { (Southwestern Power Admin.) }\end{array}$ & $\begin{array}{l}\text { Harshbarger } \\
\text { et al. } 1998\end{array}$ \\
\hline \multirow[t]{2}{*}{ Turbine venting } & 0.5 to 3 & & & $\begin{array}{l}\text { Wylie Dam, Catawba R., SC (Duke } \\
\text { Power Co.) }\end{array}$ & $\begin{array}{l}\text { Gaffney } \\
\text { et al. } 1999\end{array}$ \\
\hline & 4.5 & 0.5 & 5 & $\begin{array}{l}\text { Osage Project/Bagnell Dam, Lake of } \\
\text { the Ozarks, MO (Ameren UE) }\end{array}$ & $\begin{array}{l}\text { Jarvis et al. } \\
1998\end{array}$ \\
\hline \multirow{2}{*}{$\begin{array}{l}\text { Turbine venting } \\
\text { (aerating runners) }\end{array}$} & 7 & $<0.5$ & 5.5 to 7 & Norris Dam, Clinch R., TN (TVA) & $\begin{array}{l}\text { Hopping et } \\
\text { al. } 1997\end{array}$ \\
\hline & Up to 5.5 & & & $\begin{array}{l}\text { Wateree Dam, Wateree R., NC } \\
\text { (Duke Power Co.) }\end{array}$ & $\begin{array}{l}\text { Sigmon } \\
\text { et al. } 2000\end{array}$ \\
\hline
\end{tabular}


Table 1 (continued)

\begin{tabular}{|c|c|c|c|c|c|}
\hline \multirow[b]{2}{*}{ Technique } & \multicolumn{3}{|c|}{ DO Improvement (mg/L) } & \multicolumn{2}{|l|}{ Case Study } \\
\hline & Total & From & to & Total & From \\
\hline \multicolumn{6}{|c|}{ Tailwater Mitigation } \\
\hline \multirow[t]{2}{*}{ Infuser weir } & 6.6 & 1.0 & 7.6 & $\begin{array}{l}\text { Chatuge Dam, Hiawassee R., NC } \\
\text { (TVA) }\end{array}$ & $\begin{array}{l}\text { Hauser and } \\
\text { Morris } 1995 \text {; } \\
\text { EPRI } 1996\end{array}$ \\
\hline & 2.4 & 3.0 & 5.4 & $\begin{array}{l}\text { Lloyd Shoals Project, Okmulgee R., } \\
\text { GA (Georgia Power Co.) }\end{array}$ & Hendricks 1998 \\
\hline \multirow[t]{2}{*}{ Labyrinth weir } & 4.2 & 3.0 & 7.2 & $\begin{array}{l}\text { South Holston Dam, South Fork } \\
\text { Holston R., TN (TVA) }\end{array}$ & $\begin{array}{l}\text { Hauser and } \\
\text { Brock 1993; } \\
\text { EPRI } 1996\end{array}$ \\
\hline & 3.0 & 3.5 & 6.5 & $\begin{array}{l}\text { Canyon Dam, Guadelupe R., TX } \\
\text { (Guadelupe-Blanco River Authority) }\end{array}$ & $\begin{array}{l}\text { Hauser and } \\
\text { Morris 1995; } \\
\text { EPRI } 1996\end{array}$ \\
\hline
\end{tabular}

Table 2 Actual and anticipated improvement in tailwater dissolved oxygen (DO) at TVA hydropower plants using turbine-venting techniques. Actual uptake according to Carter 1995; expected improvements according to Hopping et al. 1997; both as given in EPRI 2002.

\begin{tabular}{|c|c|c|c|c|c|}
\hline \multirow[b]{2}{*}{ Project } & \multirow{2}{*}{$\begin{array}{c}\text { Actual DO } \\
\text { uptake } \\
(\mathbf{m g} / \mathrm{L})\end{array}$} & \multirow{2}{*}{$\begin{array}{c}\text { Target DO } \\
\text { in reservoir } \\
\text { release } \\
(\mathrm{mg} / \mathrm{L})\end{array}$} & \multirow{2}{*}{$\begin{array}{l}\text { Median DO } \\
\text { improvement } \\
\text { required } \\
(\mathrm{mg} / \mathrm{L})\end{array}$} & \multicolumn{2}{|c|}{$\begin{array}{l}\text { Expected DO improvement } \\
\text { by turbine aeration }\end{array}$} \\
\hline & & & & $\mathrm{mg} / \mathrm{L}$ & $\begin{array}{l}\text { \% of median } \\
\text { required }\end{array}$ \\
\hline $\begin{array}{l}\text { Appalachia - } \\
\text { Unit } 1\end{array}$ & 1.5 & & & & \\
\hline $\begin{array}{l}\text { Appalachia - } \\
\text { Unit } 2\end{array}$ & 1.7 & & & & \\
\hline $\begin{array}{l}\text { Appalachia - } \\
\text { combined }\end{array}$ & & 6.0 & 0.8 & 2.0 & 100 \\
\hline Blue Ridge & & 6.0 & 2.6 & 3.0 & 100 \\
\hline Boone - Unit 1 & 1.1 & & & & \\
\hline Boone - Unit 2 & 0.7 & & & & \\
\hline Boone - Unit 3 & 0.3 & & & & \\
\hline Boone - combined & & 4.0 & 0.0 & 2.0 & 100 \\
\hline Chatuge & & 4.0 & 2.9 & 1.0 & 34 \\
\hline Cherokee - Unit 4 & 2.0 & & & & \\
\hline Cherokee - all 4 units & & 4.0 & 3.8 & 2.5 & 65 \\
\hline
\end{tabular}


Table 2 (continued)

\begin{tabular}{|c|c|c|c|c|c|}
\hline \multirow[b]{2}{*}{ Project } & \multirow{2}{*}{$\begin{array}{l}\text { Actual DO } \\
\text { uptake } \\
(\mathrm{mg} / \mathrm{L})\end{array}$} & \multirow{2}{*}{$\begin{array}{l}\text { Target DO } \\
\text { in reservoir } \\
\text { release } \\
(\mathrm{mg} / \mathrm{L})\end{array}$} & \multirow{2}{*}{$\begin{array}{l}\text { Median DO } \\
\text { improvement } \\
\text { required } \\
(\mathrm{mg} / \mathrm{L})\end{array}$} & \multicolumn{2}{|c|}{$\begin{array}{l}\text { Expected DO improvement } \\
\text { by turbine aeration }\end{array}$} \\
\hline & & & & $\mathrm{mg} / \mathrm{L}$ & $\begin{array}{l}\% \text { of median } \\
\text { required }\end{array}$ \\
\hline Douglas & & 4.0 & 3.3 & 2.0 & 60 \\
\hline Fontana - Unit 1 & 1.1 & & & & \\
\hline Fontana - Unit 2 & 0.9 & & & & \\
\hline Fontana - Unit 3 & 1.3 & & & & \\
\hline Fontana - all 3 units & & 6.0 & 1.5 & 2.5 & 100 \\
\hline Hiwassee - Unit 1 & & 6.0 & 2.1 & 1.0 & 47 \\
\hline Norris - Unit 2 & 3.0 & 6.0 & 5.3 & 5.5 & 100 \\
\hline Nottely & & 4.0 & 2.9 & 1.0 & 34 \\
\hline South Holston & & 6.0 & 4.2 & 2.0 & 47 \\
\hline Tims Ford & & 6.0 & 5.6 & 4.0 & 71 \\
\hline $\begin{array}{l}\text { Watauga - Units } 1 \& 2 \\
\text { (each) }\end{array}$ & 1.5 & & & & \\
\hline Watauga - 2 units & & 6.0 & 2.0 & 2.0 & 100 \\
\hline
\end{tabular}

design, amount of air entrained, etc. Increasing DO in the turbine becomes more difficult as DO concentration approaches saturation. For example, an auto-venting turbine that can increase DO from 0 to $2 \mathrm{mg} / \mathrm{L}$ will not likely cause the same $2 \mathrm{mg} / \mathrm{L}$ increase if the intake DO starts at $3 \mathrm{mg} / \mathrm{L}$. Table 2 summarizes actual and anticipated improvement in tailwater DO at several Tennessee Valley Authority (TVA) hydropower plants using turbine-venting techniques (EPRI 2002). More advanced turbine venting designs from Voith that have been installed recently at Wateree, Thurmond, and Boone projects have an even greater capacity for improving DO. For turbine venting techniques to be most effective often requires a reduction in generation. Trials are currently underway at the Osage Hydroelectric Project (Missouri) to test turbines that have been retrofit with improved aeration systems. Two of eight units have been retrofitted with the potential to modify other units depending on the outcome of effectiveness testing. At projects with multiple turbines, the realized benefit per unit decreases as more units are brought online since higher tailwater elevation reduces the head available for inducing air.

Air or pure oxygen can be injected at several points to facilitate dissolved oxygen increases. They can be injected as fine bubbles through diffusers in the tailrace, at the bottom or surface. They can be injected into the forebay upstream of the intake (intake aeration). They can also be injected into the turbine itself, where the negative pressure (Venturi effect) created by the flowing water immediately downstream of the blades and hub will draw in air or oxygen without pumping (aerating turbine or turbine venting). Where penstocks are present, air or oxygen can be injected into the penstocks. The particular method and location of air injection can have a significant effect on the DO increase and on the amount of performance degradation that occurs.

Several methods strive to ensure that epilimnetic (surface) water enters the intakes, regardless of reservoir stratification and depth of intakes. The techniques are successful, but eliminate the cold tailwater trout fishery by release of warm water. One method uses propeller blades or pumps at the 
surface to force warmer water to the level of the intakes, locally breaking stratification. Another creates an intake structure with variable-depth intakes for selective withdrawal (useful for controlling both temperature and dissolved oxygen). Flexible curtains in the forebay can also be sued to force selective withdrawal of surface waters.

Some techniques seek to manage the oxygen resources of the larger reservoir. Hypolimnetic aeration uses diffusers to inject air or oxygen into the larger hypolimnion (not just at the intake) to reduce the rate of oxygen depletion. Other systems seek to prevent reservoir stratification by applying energy (mechanical pumping or air injection) to counteract the seasonal density differences and keep the reservoir well mixed all year.

Spill flows or other turbine bypass systems can hydraulically use the reservoir's head to create turbulence and facilitate oxygen increases. When reservoirs are full, normal spillways can be used. At other times, release gates can be opened. Where these options are not available, U-tube siphons have been installed over the dam to produce a bypass flow into which air or oxygen is introduced. Such techniques remove water from hydropower production. This type of solution is typically viewed as only a temporary one since in the long run it is more economic to employ some other fix (such as turbine venting) that does not result in as much lost generation.

A long-term solution, but one difficult to attain, is management of the watershed and reservoir so that organic productivity is reduced in the reservoir and less oxygen is consumed in the hypolimnion of the stratified reservoir. Reduced fertilizer use, tertiary sewage treatment plants, buffer zones around the reservoir and tributaries to reduce direct runoff, reforestation, erosion control on the watershed, and like measures can sometimes reverse the nutrient enrichment and high biological productivity of hydropower reservoirs. However, hydropower operators often do not control the watershed sufficiently to mandate such landscape management actions. More direct technological means at the dams are usually more practical, especially in the short run. 


\section{STUDY AND APPROACH}

\subsection{PURPOSE OF THIS STUDY}

The challenge for hydropower operators, resource managers, and environmental regulators is to select an appropriate mitigation that is effective at maintaining desirable water quality while at the same time is economically practical and maintains the project's capabilities to effectively produce power. Because it is usually not practical to install and test several different types of mitigation, decision-makers often turn to computer models to predict potential mitigation effectiveness.

The purpose of this study is to demonstrate how models that combine flow and water quality dynamics with fish energetics can be used to assess the effectiveness of mitigation to increase dissolved oxygen in dam tailwaters. The particular measures of effectiveness in which we are interested in this study include the temporal and spatial improvement in downstream DO and the resulting biological response of resident fish.

\subsection{STUDY SITE}

This report considers Center Hill Reservoir, Tennessee, as a case study to demonstrate the value of modeling dissolved oxygen and its effects on aquatic life as a tool for selecting among mitigation options. The U.S. Army Corps of Engineers (USACE), Nashville District is considering hydropower rehabilitation for the Center Hill power plant where low dissolved oxygen in summer and current minimum flow criteria for the tailwater are the two primary environmental issues being addressed. Loginetics, Inc. (2004) developed an information base for modeling this tailwater system, with emphasis on the minimum-flow issues. This work included calibration of hydrodynamic, water quality, and bioenergetic models for the Center Hill tailwater, and application of the models to quantifying downstream effects of a range of minimum-flow options. The research reported here extends the biological aspects of the dissolved oxygen modeling and analyses.

Center Hill Dam was completed in 1948 and is a 250-ft-high gravity dam that impounds the Caney Fork River at River Mile (RM) 26.6, between Cookeville and Nashville, Tennessee. The drainage area is 2,174 square miles. At full flood-control pool, the reservoir is 64 miles long with a surface area of 23,060 acres and a volume of 2,092,000 acre-ft. At the top of the power pool, the reservoir area is 18,220 acres and a volume of 1,330,000 acre- $\mathrm{ft}$. The reservoir has a mean annual inflow of 3,779 cfs, or a residence time at maximum power pool of 177 days. Caney Fork joins the Cumberland River near the tailwater of Cordell Hull Dam (at the upper end of Old Hickory Reservoir).

The powerhouse has three 45-MW turbines for a hydropower capacity of $135 \mathrm{MW}$. Peak hydraulic capacity of the powerhouse is approximately $15,000 \mathrm{cfs}$, which is exceeded about $5 \%$ of the time in the January-April period but only rarely at other times of year (flow-exceedence curves for the period 1985-2002 are provided by Loginetics, Inc. 2004). Hydropower releases are generally scheduled to meet peak electricity demands, which means that more water is released on weekdays than on weekends. The current minimum flow release requirement in the critical June 1-November 30 period for aquatic life is one generating unit for one hour within any 48-hr period. In 2003, a provisional minimum-flow operation was started that provides a 1-hr pulse of 1 unit flow every 12 hours.

Dissolved oxygen concentrations in the tailwater of Center Hill Dam vary seasonally and show typical effects of summer deoxygenation in the reservoir (Loginetics 2004). Tennessee water quality standards for DO require $6 \mathrm{mg} / \mathrm{L}$ for trout waters, even for artificial tailwaters. In April 2003, 
dissolved oxygen in the turbine releases were $10.5 \mathrm{mg} / \mathrm{L}$ and varied between that 10.2 and $11.2 \mathrm{mg} / \mathrm{L}$ in the river to RM 11, at temperatures that increased from 9.1 to $11.6{ }^{\circ} \mathrm{C}$. In contrast, a similar longitudinal survey in October 1997 (after summer stratification) revealed dam releases with 0.9 $\mathrm{mg} / \mathrm{L}$ dissolved oxygen, increasing to $3.2 \mathrm{mg} / \mathrm{L}$ at RM 11. In October 2002, releases contained about $1.5 \mathrm{mg} / \mathrm{L}$ increasing to $4.1 \mathrm{mg} / \mathrm{L}$ at RM 11 . In an intermediate period of summer hypolimnetic deoxygenation (July 1997), releases were near $3.5 \mathrm{mg} / \mathrm{L}$ and increased to $5 \mathrm{mg} / \mathrm{L}$ by RM 16. Continuous monitoring at RM 18.2 for several days in August 1996 showed marked daily fluctuations in dissolved oxygen, reflecting the daily generation pattern. As flow from the dam increased in response to daily electricity demand, the dissolved oxygen at this point midway between the dam and the mouth dropped from near $8 \mathrm{mg} / \mathrm{L}$ to near $3 \mathrm{mg} / \mathrm{L}$.

USACE has tried a variety of measures to improve DO below Center Hill Dam including releasing water through the sluiceway, altering the loading on turbines, adding hub baffles, and turbine venting (TWRA 2003). Releasing well-oxygenated surface water through the sluiceway increased tailwater DO, but also increased temperature to the point that it was lethal to trout. Operating turbines at $1 / 2$ and $3 / 4$ load produced a slight increase in discharge DO. Adding hub baffles and turbine vents (completed in December 2001) to all three turbines increased DO during deficit periods, but only by $1.5 \mathrm{mg} / \mathrm{L}$ with one turbine operating and only $0.5 \mathrm{mg} / \mathrm{L}$ with three turbines operating.

The Loginetics, Inc. study initiated the use of simulation models for evaluating instream issues, including dissolved oxygen regeneration and effects at Center Hill. The primary modeling objective was to quantify relative effects of various minimum flow options compared to the base case (no minimum flow) for Nashville District. The investigation considered continuous flows, pulsed flows, and reregulation weirs as potential means to provide a minimum flow at Center Hill. The primary effects of interest were how higher flows might affect water temperature and physical habitat with regard to trout requirements. Effects of these options were explored assuming critical low ambient flow conditions and within the context of typical historical operations. These results were compared to standard habitat suitability indices for trout spawning, juveniles, and adults, which illustrated the markedly degraded conditions for aquatic life. As an aside, the study also considered possible effects of revised minimum flows on other water quality parameters, specifically dissolved oxygen. Clearly, however, there is much to be gained by further refinement of both physical and biological-effects models for dissolved oxygen in dam tailwaters.

The Tennessee Wildlife Resources Agency stocks rainbow and brown trout into Caney Fork River below Center Hill Dam several times a year. In April 2003 they stocked 20,000 brown trout which were tagged with coded-wire tags prior to stocking so that they could be identified and their growth tracked during subsequent sampling. From April 2003 through April 2004, a Tennessee Technological University (TTU) graduate student measured the lengths and weights of recaptured fish on about a monthly basis. These data are reported in a recently completed Masters thesis (Meerbeek 2005) and were used for calibration of the fish growth model. Additional raw data were also provided for this analysis by P. Bettoli of TTU (personal communication). The observed weights suggest growth in late spring, followed by a period of little or no growth from July through September, and then growth throughout the fall and winter (Fig. 2.1).

To investigate whether growth rates varied with distance from the dam, we calculated average weights of recaptured fish for three river reaches: Below Dam (RM 24.5-26.5), Upper (RM 19.5-26.5), and Lower (RM 12.5-19.5). Note that the Upper reach includes the Below Dam reach. 


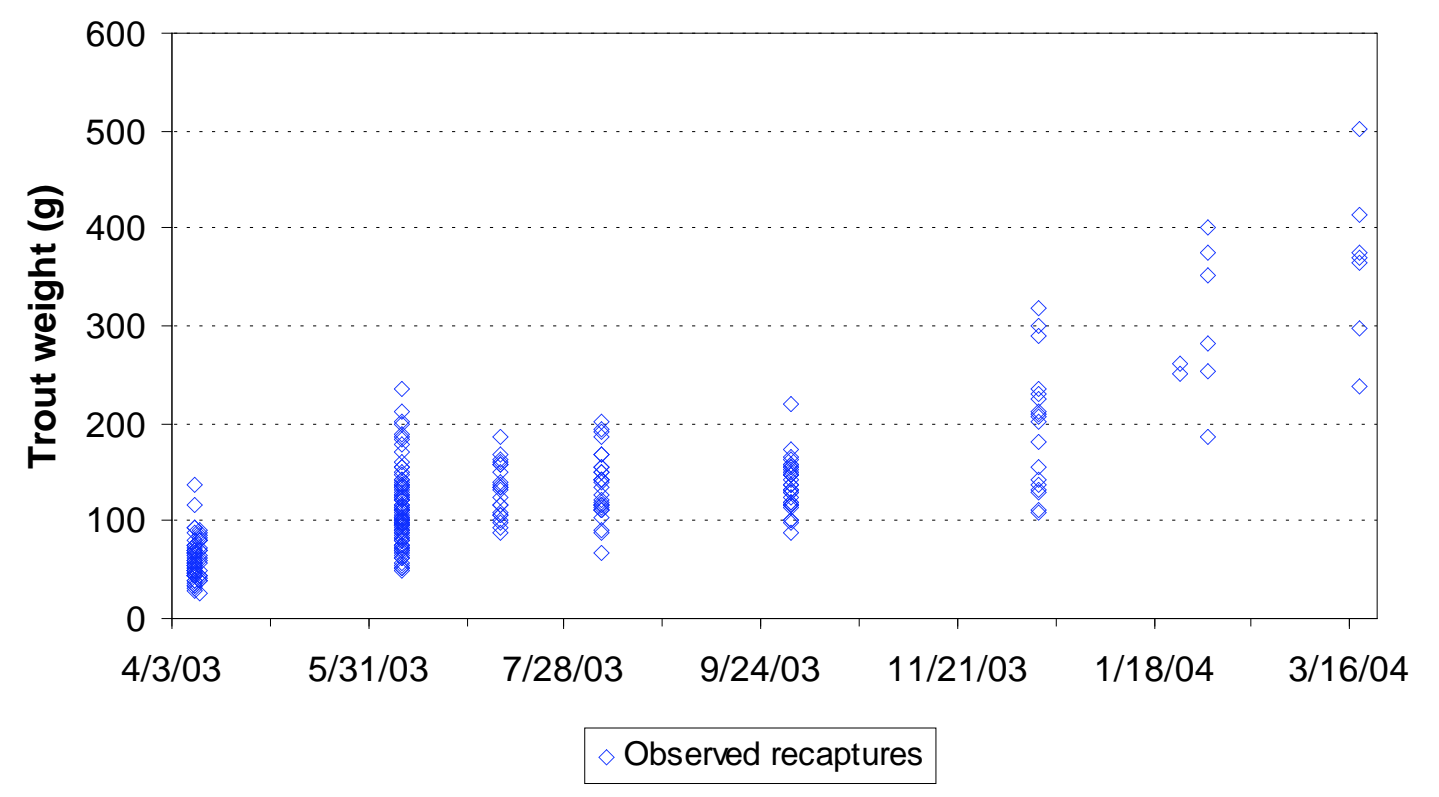

Fig. 2.1. Weight of 286 individual brown trout captured in Caney Fork River from April 2003 through April 2004.

Although the small sample size prevents us from doing a rigorous statistical analysis, the data suggest a spatial variation in growth rates (Fig. 2.2). Growth at all reaches was similar through the first of October, but then it appears fish residing closer to the dam (Below Dam and Upper reaches) grew faster during fall and winter than fish further downstream (Lower reach). This advantage was maintained or increased during the early spring. Possible reasons for this differential growth among reaches are addressed later in this report. One assumption of this simple analysis is that fish did not move after establishing residency in a location and thus their growth represented the environmental conditions at that location.

\subsection{MODEL DESCRIPTION}

We used a combination hydrodynamic/water quality/fish growth model to evaluate the potential for effective mitigation of low dissolved oxygen in the tailwaters of Center Hill Dam. The particular model used here was developed by TVA hydraulic engineers and biologists and has been used for many years to assess the effects of hydropower dam operations on river water quality (Hauser and Bender 1987, Hauser 1990, Bevelhimer et al. 1997, Shiao and Yeager 1997). The model has been revised and enhanced over the past 10 years and now includes the capability to also assess effects on fish habitat and fish growth. 


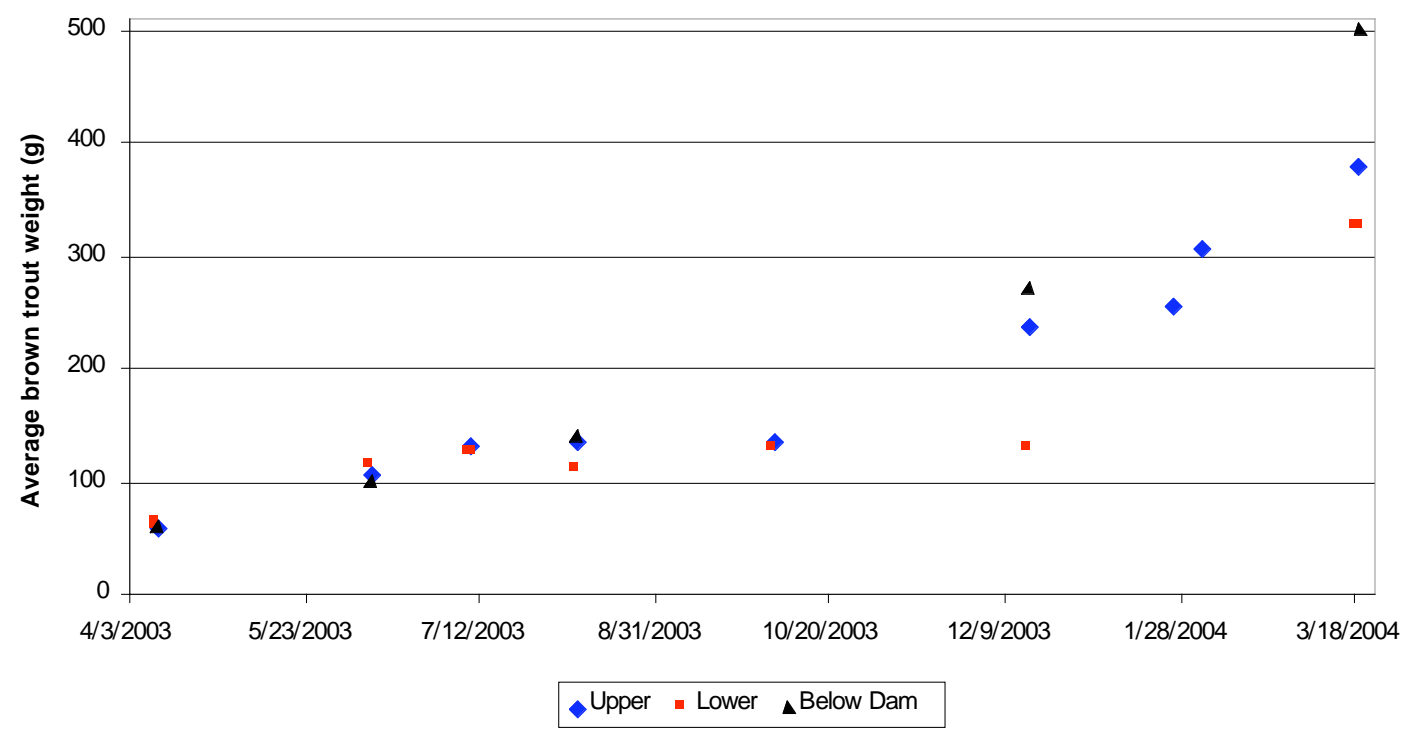

Fig. 2.2. Average brown trout weight for three river reaches: Below Dam (RM 24.5-26.5), Upper (RM 19.5-26.5), and Lower (RM 12.5-19.5).

The hydrodynamic model ADYN solves one-dimensional equations for conservation of mass and momentum for irregularly shaped rivers and reservoirs using a four point implicit finite difference scheme with weighted spatial derivatives or a McCormack explicit scheme (Hauser 2003). Channel resistance is accounted for using an adaptation of the empirically-based Manning's roughness formulation that allows resistance to vary with flow depth. ADYN can be used to study unsteady river and reservoir hydraulics where the following are of interest:

- water or wave travel times;

- routing of natural flow waves or planned pulsed flows;

- effects of hydropower dams, weirs, etc. at downstream or internal boundaries;

- flow reversals;

- interactions with dynamic tributaries at channel junctions;

- multiple tributary systems with multiple internal boundary conditions;

- effects of distributed or point lateral inflows;

- flow and elevation hydrographs at locations between stream gauge sites; and

- effects of channel geometry and roughness on flow and water surface elevation.

The water quality model RQUAL solves the mass transport equation with the same numerical scheme used in the ADYN hydrodynamic model and is used in conjunction with ADYN to compute water temperature, oxygen demand, and dissolved oxygen in rivers and reservoirs where the one dimensional longitudinal flow assumption is appropriate. The AYDN and RQUAL models are wellsuited for narrow confined tailwater reaches, such as that of the Center Hill Dam, in which the transverse and vertical gradients of flow velocity and water quality are negligible. The following can be studied with the combined models:

- waste load allocation;

- effects of location, magnitude, and timing of interventions seeking to improve water temperature and quality;

- dilution and degradation of wastes;

- effects of thermal loadings and atmospheric heat exchange on stream temperature; and 
- effects of natural or artificial re-aeration, diurnal photosynthesis and respiration by macrophytes, waste loads, tributary inflows, and variable flow regimes on dissolved oxygen levels.

The fish growth model FISH uses a bioenergetics approach that predicts growth by balancing an energy budget that includes energy intake through food consumption and energy loss via routine metabolism, activity, and food processing costs. Fish bioenergetics models are typically used to evaluate the effects of food abundance or water temperature on fish growth (Adams and Breck 1990). The particular model used here also includes the indirect effects of dissolved oxygen level on growth via direct effects on food consumption. This is a component that is not found in most bioenergetics models, and is the reason we are using this particular model package to evaluate the benefit of tools like this to assess mitigation to improve dissolved oxygen in dam tailwaters. The fish growth model can be used to predict the effects of temperature and dissolved oxygen dynamics on:

- weight gain through time of individuals or populations;

- food consumption rates and resulting effects on prey abundance;

- efficiency of conversion of food to body mass; and

- seasonal patterns in prey abundance and the resulting limitations on predator growth.

The ADYN and RQUAL modeling system can also be linked to a fish habitat model RHAB that characterizes change in available habitat under various operational scenarios.

The spatial scale of the model includes 26.5 miles of the Caney Fork River from the Center Hill Dam downstream to the mouth of the river and its confluence with the Cumberland River. Within this reach we were mostly interested in the 14 miles below the dam where the trout population is managed as a sport fishery. The temporal scale of this study was primarily from April 2003 when brown trout with identification tags were stocked throughout the river to April 2004 when a study to assess the growth of those stocked fish was concluded.

\subsection{INPUT DATA}

For the exercises reported in this study, we began with a calibrated model for the Center Hill tailwater and updated input files as needed to reflect the conditions during the period of interest (March 2003 through April 2004). A brief description of model input data follows.

\subsubsection{Hydrodynamic Model Data Requirements}

ADYN requires three major types of information:

- river geometry,

- boundary conditions, and

- numerical solution control.

Reach geometry input includes information for each model "node" and the overall structure of the river system. ADYN models the flow in river and reservoir systems by establishing a set of computational nodes (specific locations) to represent the system. The nodes are identified with numbers that increase in the downstream direction. Geometric input for each node may be provided by the user as cross-sectional information (e.g., elevations at specified distances along the cross section, Manning's $n$ at specified sections of the cross-section, etc.) or may be interpolated by the model from neighboring nodes. River cross-section values were included for 122 nodes from the dam to the mouth of the Caney Fork River. 
The model allows the river system to be constructed of one main channel, up to eight dynamic tributaries, and up to 20 lateral inflows. Along each reach, the user may specify the presence of internal boundaries (such as dams and weirs) or of lateral inflows (such as creeks, rivers, irrigation withdrawals, or a distributed flow along a channel). We used 19 lateral inflows to represent small tributaries and areas of general runoff along the Caney Fork (Fig. 2.3).

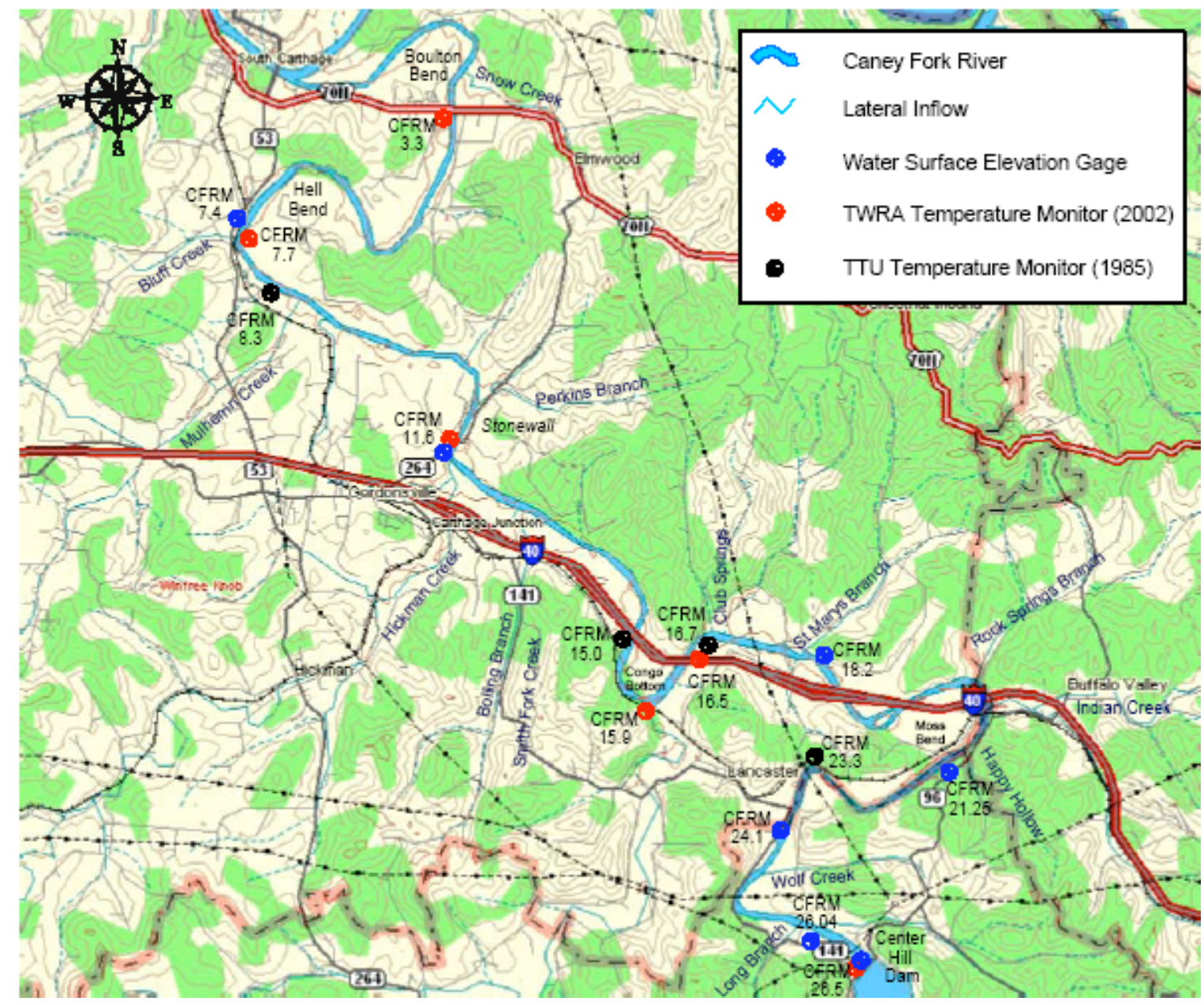

Fig. 2.3. Map of the Caney Fork River below Center Hill Dam. The dam is at the lower right and the confluence with the Cumberland River is at the upper left. (Source: Loginetics, Inc. 2004)

Boundary condition input provides flow information for each type of boundary: upstream end of the main channel or tributary, downstream end of the main channel or tributary, internal boundary, and lateral inflow.

Upstream boundary information may be provided as a discharge hydrograph (flow as a function of time) or as an elevation hydrograph (elevation as a function of time). Hourly dam discharge data were obtained from USACE for the upstream boundary condition (Fig. 2.4 and Fig. 2.5). These data indicate that the conditions during the period of interest display rapid and frequent fluctuations in flow which is typical for peaking operations like the Center Hill project. Flows from the dam fluctuate between zero when not generating around 10,500 cfs when all three turbines are running, with periods near 3,500 cfs (one turbine) and 7,000 cfs (two turbines). 


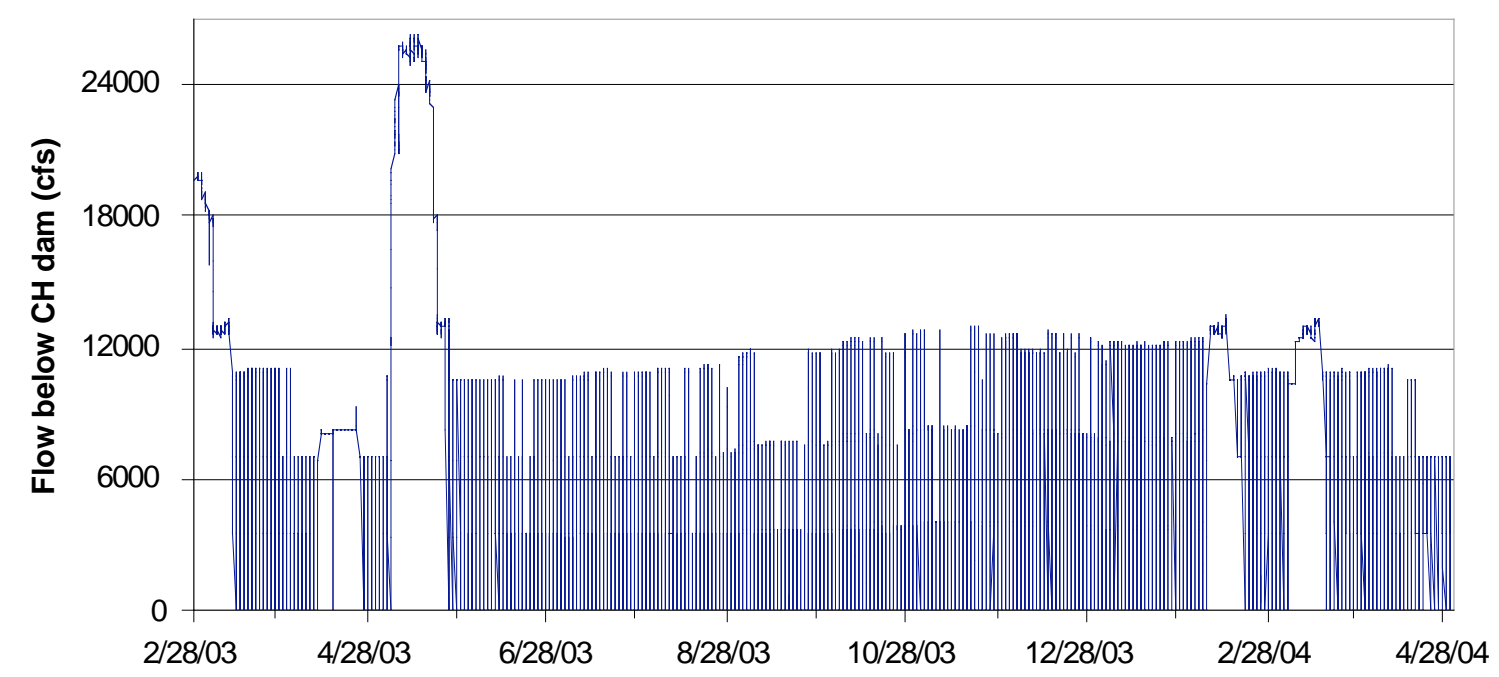

Fig. 2.4. Hourly flow from Center Hill Dam, which shows periods when one (approx. 3,500 cfs), two (approx. 7,000 cfs), or three (approx. 10,500 cfs) turbines are operating intermittently between periods of no flow. Five periods are evident when natural flows either exceeded hydraulic capacity of the powerhouse or turbines were operated 24 hours per day.

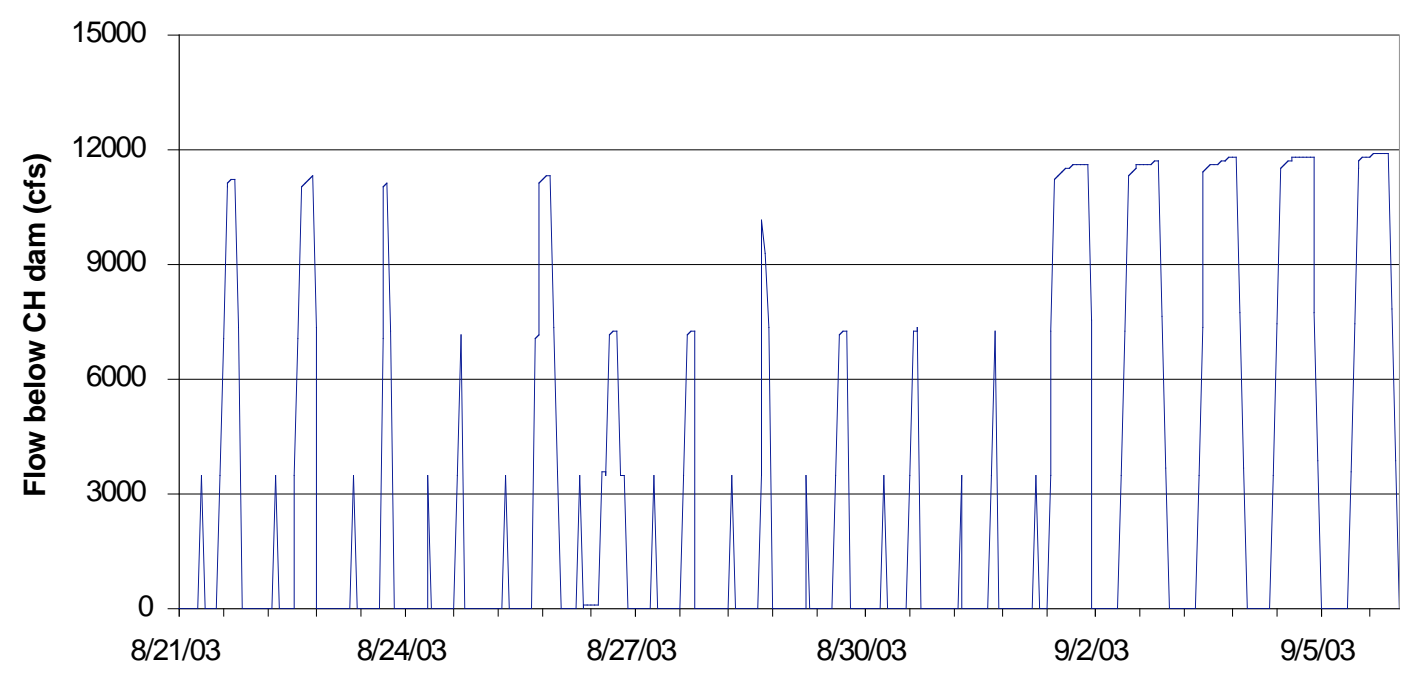

Fig. 2.5. A finer temporal scale view of flow from the Center Hill Dam illustrating the daily peaking operation of the project.

Downstream boundary information may be given in the form of an elevation vs. discharge rating curve (flow as a function of water elevation), a discharge hydrograph, or an elevation hydrograph. We used surface elevations collected from a gage at the mouth of the Caney Fork River. Internal boundary conditions are specified as an elevation vs. discharge rating curve or as an elevation hydrograph. Lateral inflows are expressed as inflows (or withdrawals) versus time. We used daily flow data from a USGS gage at Smith Fork Creek (Fig. 2.6), a tributary near RM 16, to estimate daily flow at the other 18 lateral inflows based on a direct relationship between daily flow and drainage 
area as calculated for Smith Fork Creek. A comparison of flow duration curves for Smith Fork Creek and the Center Hill Dam release illustrates the difference between flows from the project and the natural hydrograph (Fig. 2.7).

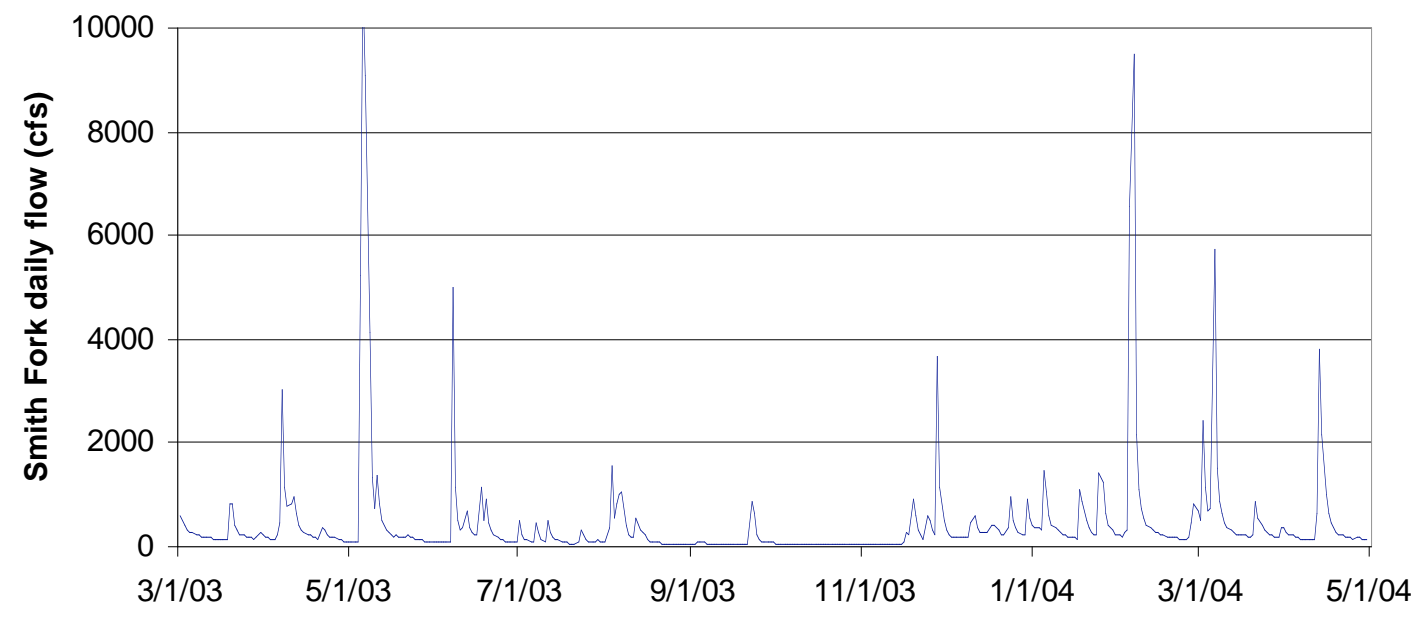

Fig. 2.6. Daily flow at Smith Fork Creek, the largest tributary to the Caney Fork River downstream of the dam, illustrating the difference between natural flow dynamics for the region and those below the dam.

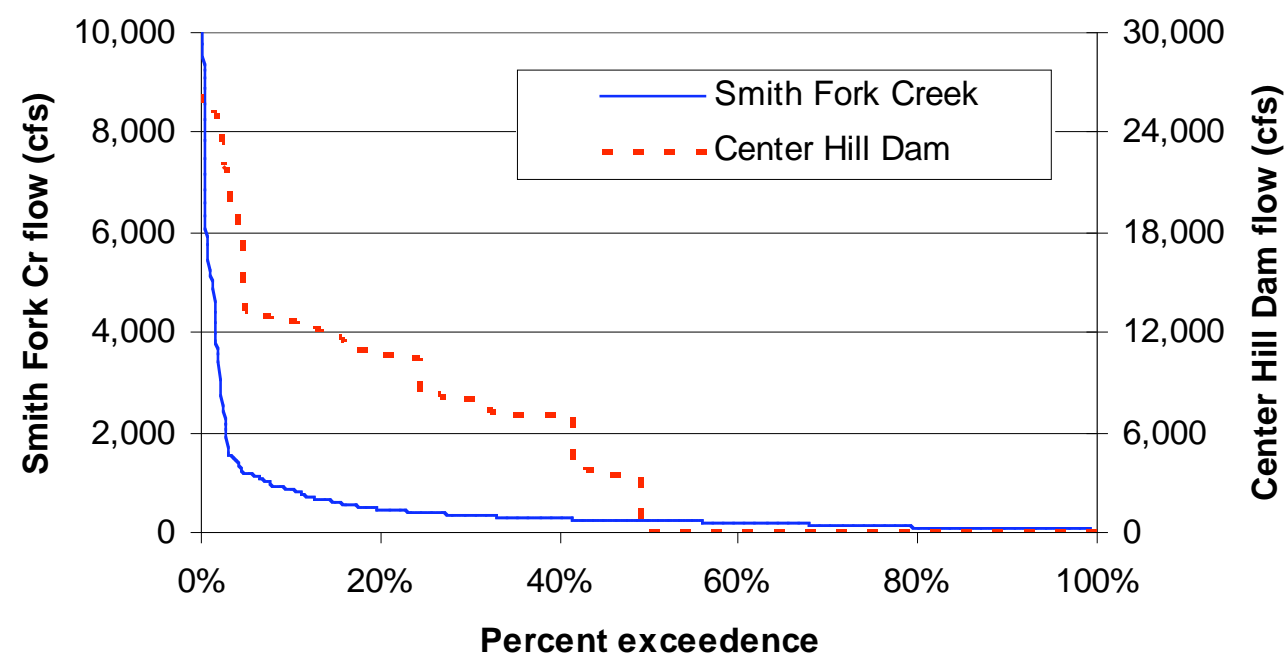

Fig. 2.7 Flow duration curves for Smith Fork Creek and Center Hill Dam release for the period 1 March 2003 to 30 April 2004. 
Numerical solution control information specifies the use of the implicit or explicit computational schemes, weighting factors, and convergence tolerances. These values were obtained from the existing model. A four-point implicit scheme was the type of numerical solution used with a weighting factor of 0.9 . The computational time step for the model was hourly.

\subsubsection{Water Quality Model Data Requirements}

RQUAL requires four major types of input information: hydrodynamic updates, meteorology, boundary conditions, and miscellaneous coefficients and control input.

The RQUAL model uses output from ADYN to update river hydrodynamics (flow, velocity, river depth, etc.).

Meteorological parameters required by RQUAL include:

- air (dry bulb) temperature,

- dew point temperature,

- cloud cover,

- barometric pressure,

- wind speed, and

- solar radiation.

Each of these parameters, except solar radiation, is normally measured on an hourly basis at major airports. Data for this model were obtained from hourly monitoring records at the Nashville airport. Solar radiation is computed from air temperature and cloud cover at desired locations (based on latitude and longitude).

The RQUAL boundary conditions input file contains concentrations or mass loadings at an hourly interval for heat (i.e., water temperature), dissolved oxygen, biological oxygen demand, and/or nitrogenous biochemical oxygen demand at the upstream boundary condition and other lateral inflow sites. The model computes temperature at all other nodes, including internal boundaries. Because these data in particular are crucial to the predictions of the model, their derivation is discussed below in detail.

Water Temperature - Specific records of dam discharge temperatures were not available, however, researchers at TTU collected temperature data with a continuous monitoring device located about 200 meters downstream of the dam during most of the period of interest. The temperatures at this location should be virtually the same as that at the discharge during periods of generation. When the plant is not generating the temperatures typically warm up rapidly because of the low flow. Therefore, we used the daily minimum at the monitoring site as the temperature of the dam release for that day (Fig. 2.8). These data correspond well with occasional grab samples collected by other investigators. No daily variation was incorporated as the water temperature at the location of the intake on the reservoir side of the dam likely undergoes insignificant within-day fluctuation. Some interpolation of temperatures was necessary for periods of missing records. This temperature was also used as the temperature of three lateral inflows that represent points of leakage from the dam into the tailwaters. 


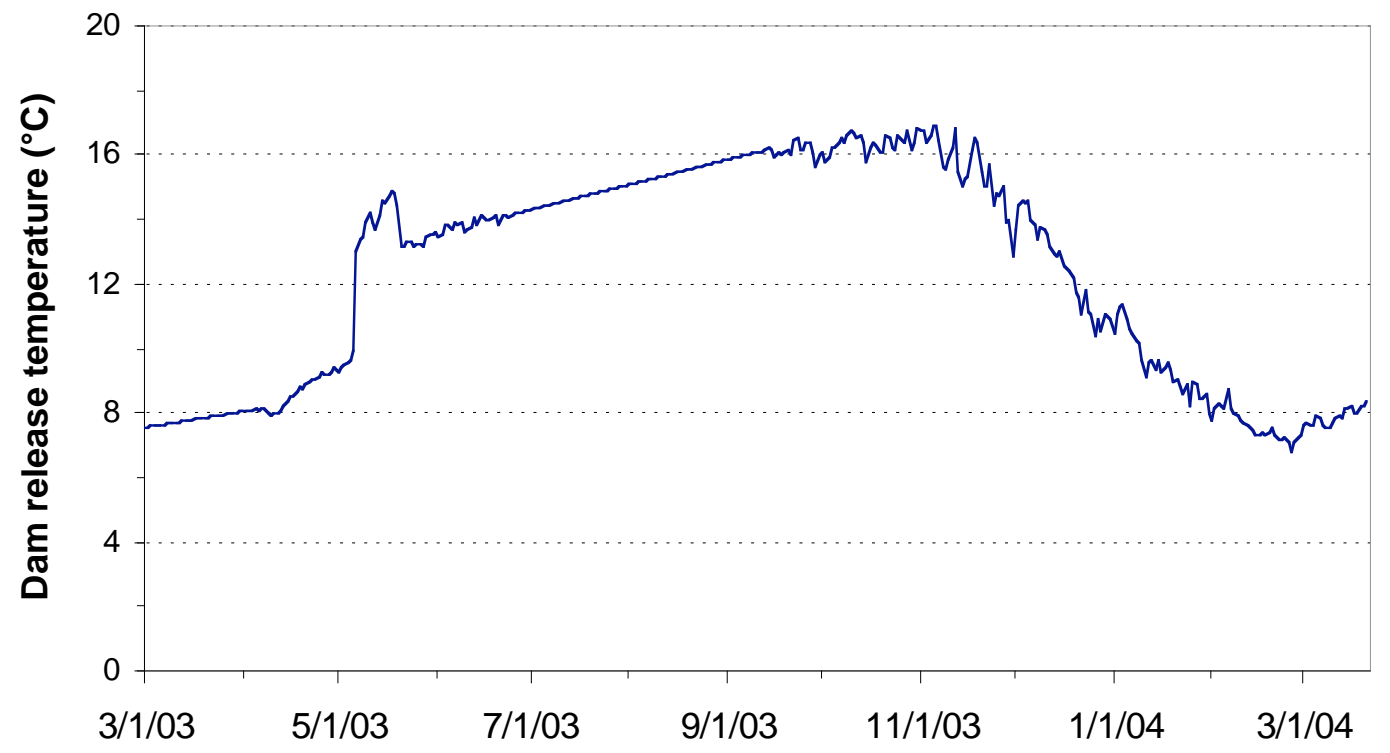

Fig. 2.8. Daily minimum temperature in the tailrace of Center Hill Dam which was used to represent the temperature of the dam discharge. Values for periods without data in March and late June to September were interpolated.

Daily temperature data for the tributary streams were not available, but 12 years of periodic grab samples from Smith Fork were. We used these data to derive a relationship between day of the year (Julian day) and mean daily temperature (Fig. 2.9) which we used to estimate daily mean temperature for all the tributaries. Because small streams typically exhibit significant daily temperature variation, we included a daily variation of $+/-10 \%$ of the mean that was distributed evenly across the $24-\mathrm{h}$ day.

Dissolved Oxygen - Continuous DO data are not available for the discharge from the dam. However, 12 years of periodic grab samples of water quality are available from which we derived a relationship between DO and Julian day (described by 3rd order polynomial equation; Fig. 2.10). Because we did not believe that the derived equation accurately reflected the period of lowest DO during the late summer (days 220-320), DO during this time was adjusted downward up to $1 \mathrm{mg} / \mathrm{L}$ reduction on day 270 (see Fig. 2.10). This correction more closely approximates a recorded value of $1.7 \mathrm{mg} / \mathrm{L}$ in the upper reach on 3 Oct 2003 (day 276; Meerbeek 2005). The DO derived for the dam release was also used for two of the three leakage inflows (the third is discussed below).

Absent any information on DO concentrations in the tributaries, we assumed that each was at $100 \%$ saturation. The $100 \%$ saturation value was calculated as a function of temperature for each hourly value. We also assigned a $100 \%$ saturation value to the dam leakage at right abutment of the dam which is fully re-aerated as it cascades down a rock face into the tailwater. This leakage represents a constant input of about $75 \mathrm{cfs}$. 


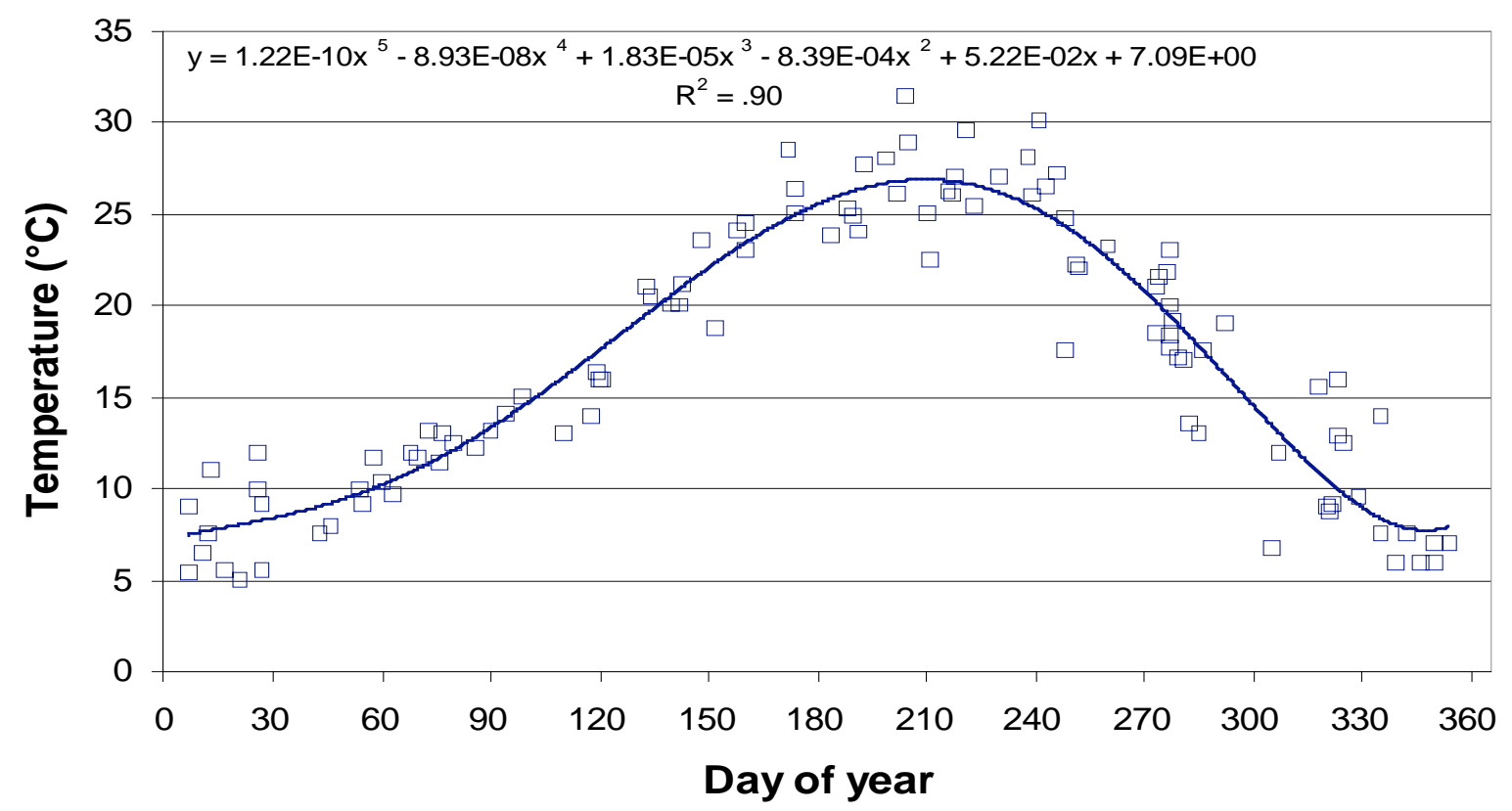

Fig. 2.9. Fitted relationship (5th order polynomial) between water temperature in Smith Fork Creek and Julian day for data collected since 1991.

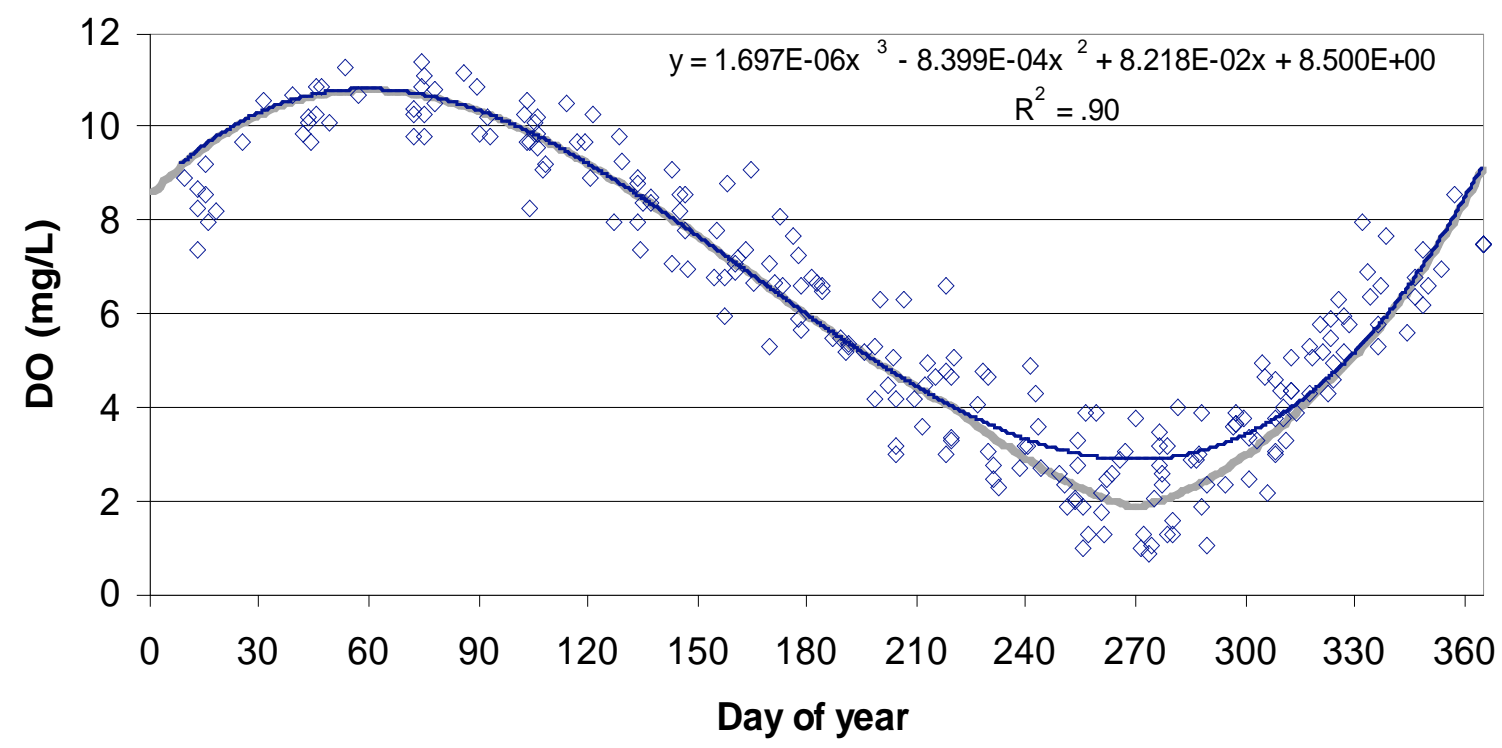

$\diamond$ Grab samples $\quad$ Adjusted curve

— Poly. (Grab samples)

Fig. 2.10. Polynomial relationship between day of year and dissolved oxygen derived from twelve years of grab samples below the Center Hill Dam. The curve was adjusted slightly to better capture periods when DO is lowest in late summer. 
NBOD and CBOD - Nitrogenous biological oxygen demand (NBOD) and carbonaceous biological oxygen demand (CBOD) are important variables that control the removal of available dissolved oxygen from the water by various biological processes. In the absence of data for the period of interest we used the same values as used in the Loginetics model: NBOD $=0.43 \mathrm{mg} / \mathrm{L}$ for the dam release and dam leakage and $0.26 \mathrm{mg} / \mathrm{L}$ for the tributaries and other lateral inflows; and CBOD $=2.0$ $\mathrm{mg} / \mathrm{L}$ for all locations. These values were based on averages of 1974-1976 water quality data measured at RM 26.5.

NBOD and CBOD - Nitrogenous biological oxygen demand (NBOD) and carbonaceous biological oxygen demand (CBOD) are important variables that control the removal of available dissolved oxygen from the water by various biological processes. In the absence of data for the period of interest we used the same values as used in the Loginetics model: NBOD $=0.43 \mathrm{mg} / \mathrm{L}$ for the dam release and dam leakage and $0.26 \mathrm{mg} / \mathrm{L}$ for the tributaries and other lateral inflows; and CBOD $=2.0$ $\mathrm{mg} / \mathrm{L}$ for all locations. These values were based on averages of 1974-1976 water quality data measured at RM 26.5.

RQUAL also requires water quality coefficients and other miscellaneous site-specific input. These include:

- latitude and longitude of the river,

- time of morning fog lift (before which solar radiation is reduced by 80 percent),

- azimuth of river at each node,

- bank width,

- tree height or effective barrier height at each node,

- coefficients in a wind speed function used for evaporative cooling,

- effective channel bed thickness (upper layer) for bed heat conduction,

- effective channel bed thickness (deep layer),

- thermal diffusivity of bed material,

- bed heat storage capacity,

- fraction of solar radiation absorbed in top 0.6 meter of water,

- albedo of bed material,

- fraction of solar radiation absorbed by shaded water, and

- fraction of drybulb/dewpoint depression by which drybulb is cooler over shaded water.

Miscellaneous input data not readily available at each site can be estimated from the literature and refined through the model calibration process. Once the model is calibrated, the coefficients and constants remain fixed for subsequent simulation runs. These values are normally consistent through time and we used the same values as those in the previously calibrated Center Hill model (Loginetics, Inc. 2004).

\subsubsection{Fish Growth Model Data Requirements}

The primary input data for the fish bioenergetics model are species-specific variables that describe the relationships between water quality parameters (temperature and DO) and various behavioral or physiological functions (feeding, metabolism, food processing, waste elimination, etc.). These values are established for many species based on laboratory experiments. The values we used for brown trout have been used by others in similar bioenergetics models (Shiao et al. 1993) and are derived from laboratory studies by Elliot (1976). The values we used for brown trout result in key temperature relationships shown in Fig 2.11. At maximum consumption, these relationships would result in maximum growth at about $13^{\circ} \mathrm{C}$. 
Input variables also control the effect of DO on food consumption via an appetite multiplier that is a function of ambient DO. Under the configuration used in our modeling food consumption begins to decline at DO less than $6 \mathrm{mg} / \mathrm{L}$ and is zero at DO less than $2 \mathrm{mg} / \mathrm{L}$ (Fig. 2.12). This relationship is similar to that described for the effects of DO on growth for another salmonid species by Herrmann et al. (1962)

Additional information needed for the fish growth model is the date and size of trout at the beginning of the simulation (69 $\mathrm{g}$ on 3 April 2003) which we obtained from stocking records (Meerbeek 2005).

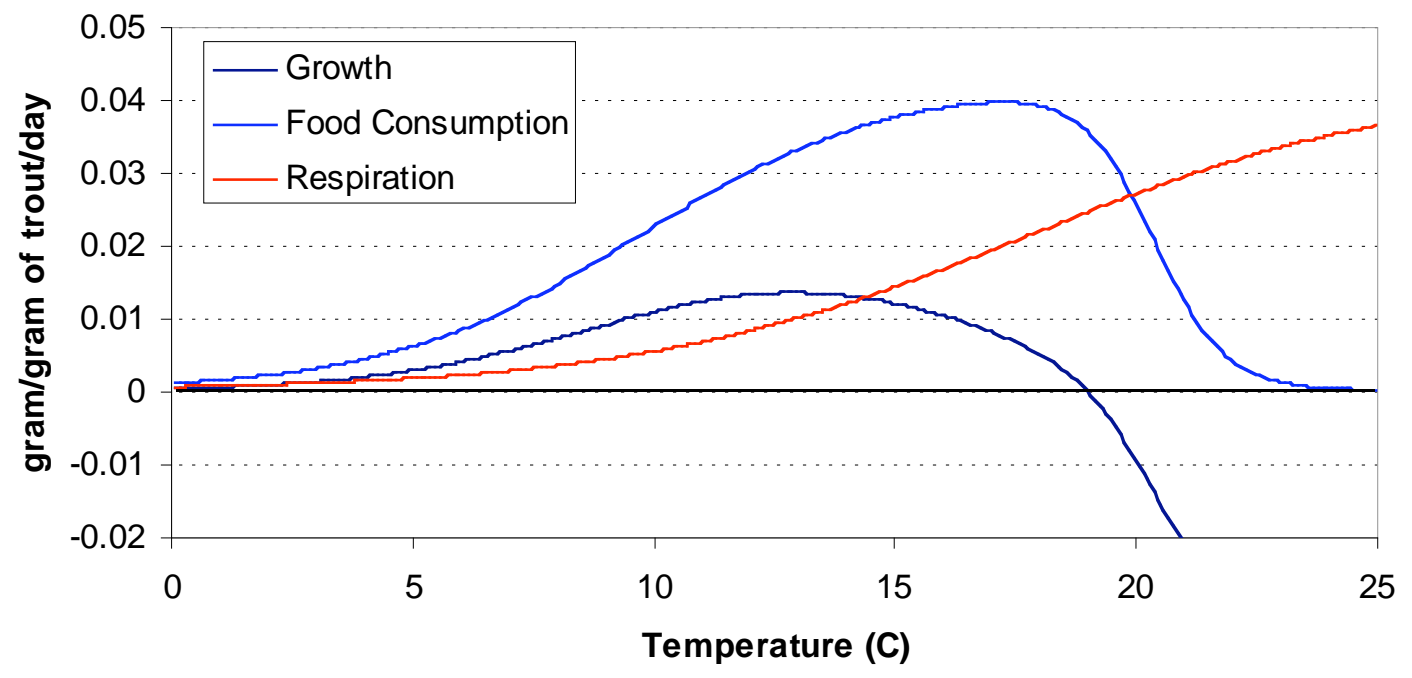

Fig. 2.11. Relationships between food consumption, growth, and respiration for brown trout in the fish growth model based on equations and parameters used in the model.

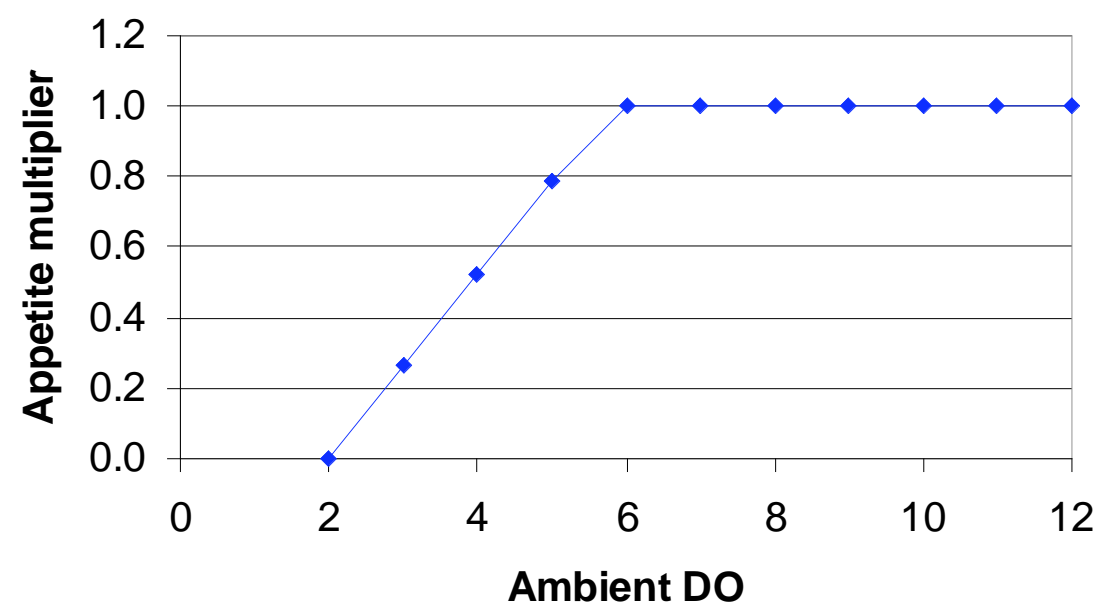

Fig. 2.12. Relationship between ambient DO and the appetite multiplier used to restrict food consumption at low DO. 


\subsection{MODEL EXPERIMENTS}

The first set of simulations was for model calibration which was accomplished by adjusting input parameters such that model predictions approximate observed measurements. The results of the final calibrated simulation established the baseline conditions to which other simulations were compared.

The second set of simulations provided examples of how the model can be used to assess mitigation at the turbine or powerhouse outfall (as opposed to mitigative measures in the forebay or the tailwater). Examples of such mitigation include turbine venting, draft tube venting, and air injection. We simulated different levels of improvement by these methods by increasing the DO level of the water being released from the dam in the RQUAL boundary conditions input file. In four different simulations, we used the existing DO levels but with simulated elevated DO to 3, 4, 5, and 6 $\mathrm{mg} / \mathrm{L}$, respectively (Fig. 2.13). This resulted in higher DO during the summer when DO levels are typically low. Mitigation of this sort typically has no significant effect on water temperature.

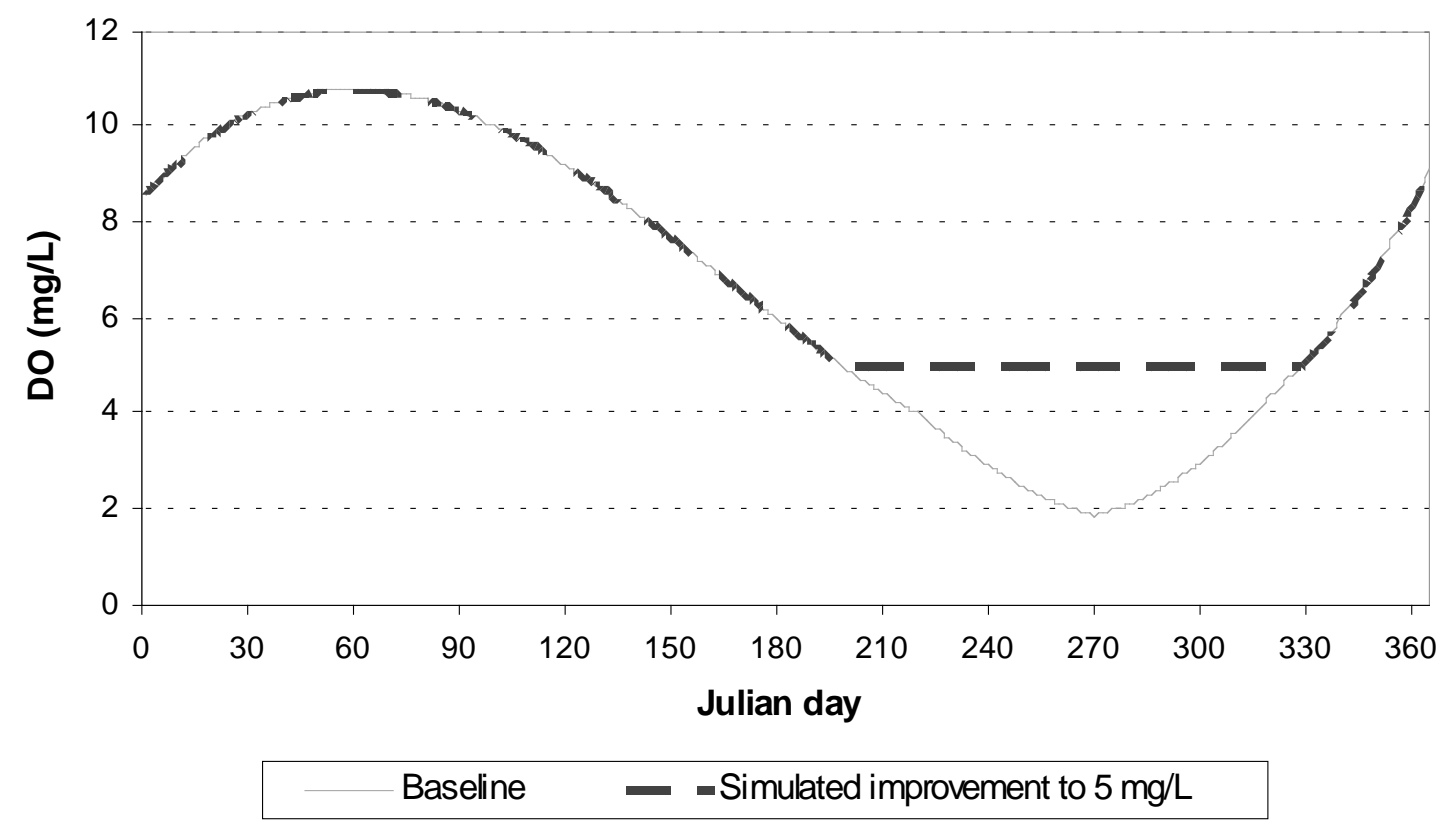

Fig. 2.13. Example of dam release DO levels for simulated improvement to $5 \mathrm{mg} / \mathrm{L} \mathrm{compared} \mathrm{to} \mathrm{the}$ baseline.

The third set of simulations was designed to simulate forebay mitigation, such as hypolimnetic aeration and forebay mixing. These methods usually result in a mixing of the water column which results in an increase in temperature of the water being passed through the turbine. For this simulation we combined a DO level increase to $5 \mathrm{mg} / \mathrm{L}$ for water released at the dam with an increase in temperature of $3^{\circ} \mathrm{C}$ on days when DO was increased. 


\section{RESULTS}

\subsection{MODEL CALIBRATION AND BASELINE SIMULATION}

\subsubsection{Water Quantity and Quality}

The water quality was applied as calibrated in the Loginetics Inc. (2004) study. Fig 3.1 and Fig 3.2 illustrate the difference among reaches in hourly tailwater temperature and DO, respectively. The large amount of daily variation in both temperature and DO are largely a result of the peaking operation which varies dam releases; diurnal variation in air temperature and solar radiation also contributes to the diurnal variation in water quality. As expected, as water moves downstream both temperature and DO increase slightly, however, the amount of improvement is not as great as might be expected in many other rivers that have a greater natural capacity for aeration. Figure 3.3 combines the temporal and spatial variation in DO in a different way. Each panel shows a 10-day mean and range in DO from Center Hill Dam (RM 26.5) to the river mouth (RM 0). In addition to the downstream increase in DO, the figure also illustrates a decrease in the range of DO as water moves downstream, as a result of increasing minimum values, decreasing maximum values, or both. 

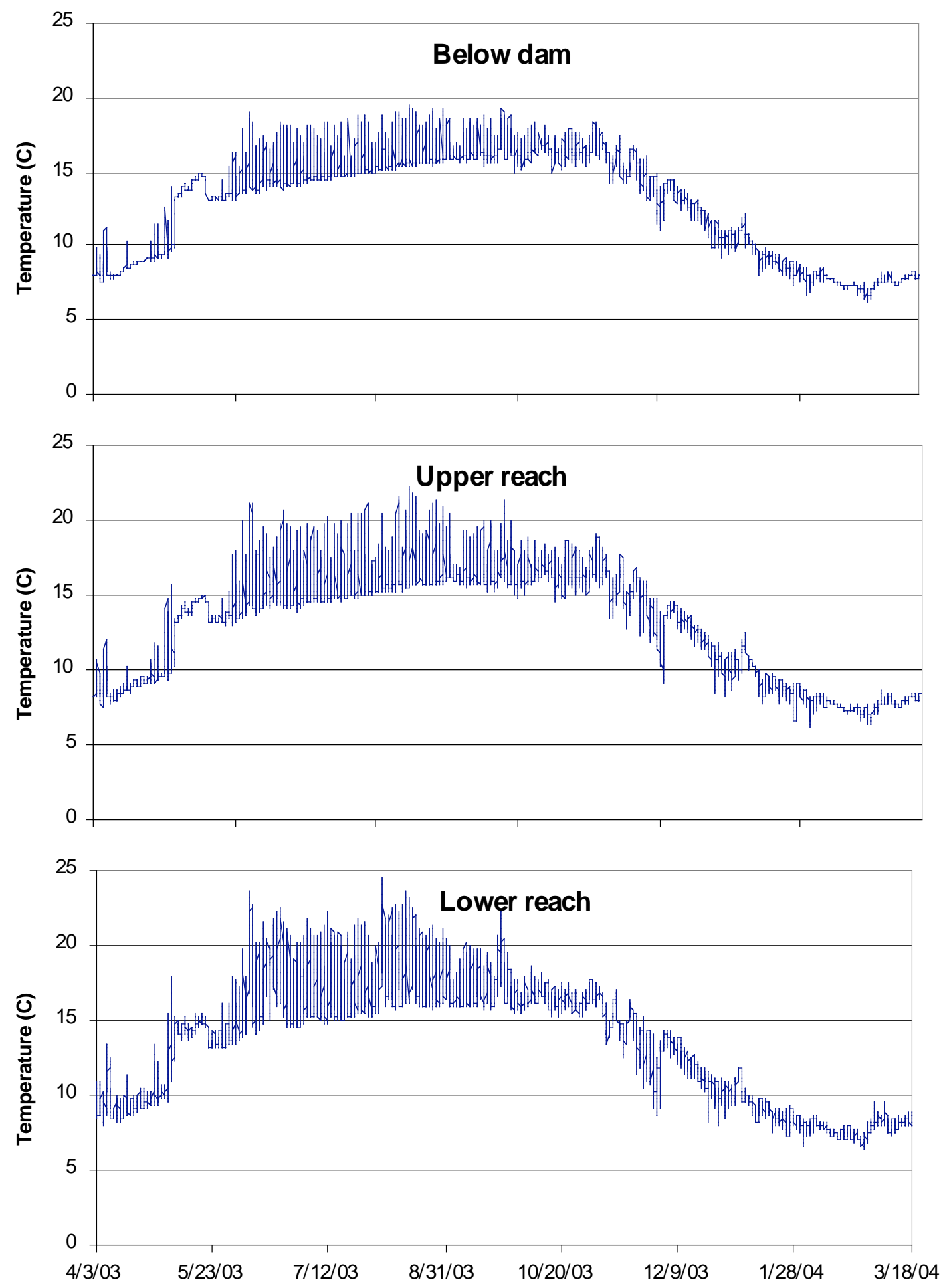

Fig. 3.1. Model generated temporal profile of hourly temperature for three reaches below Center Hill Dam under baseline conditions. 

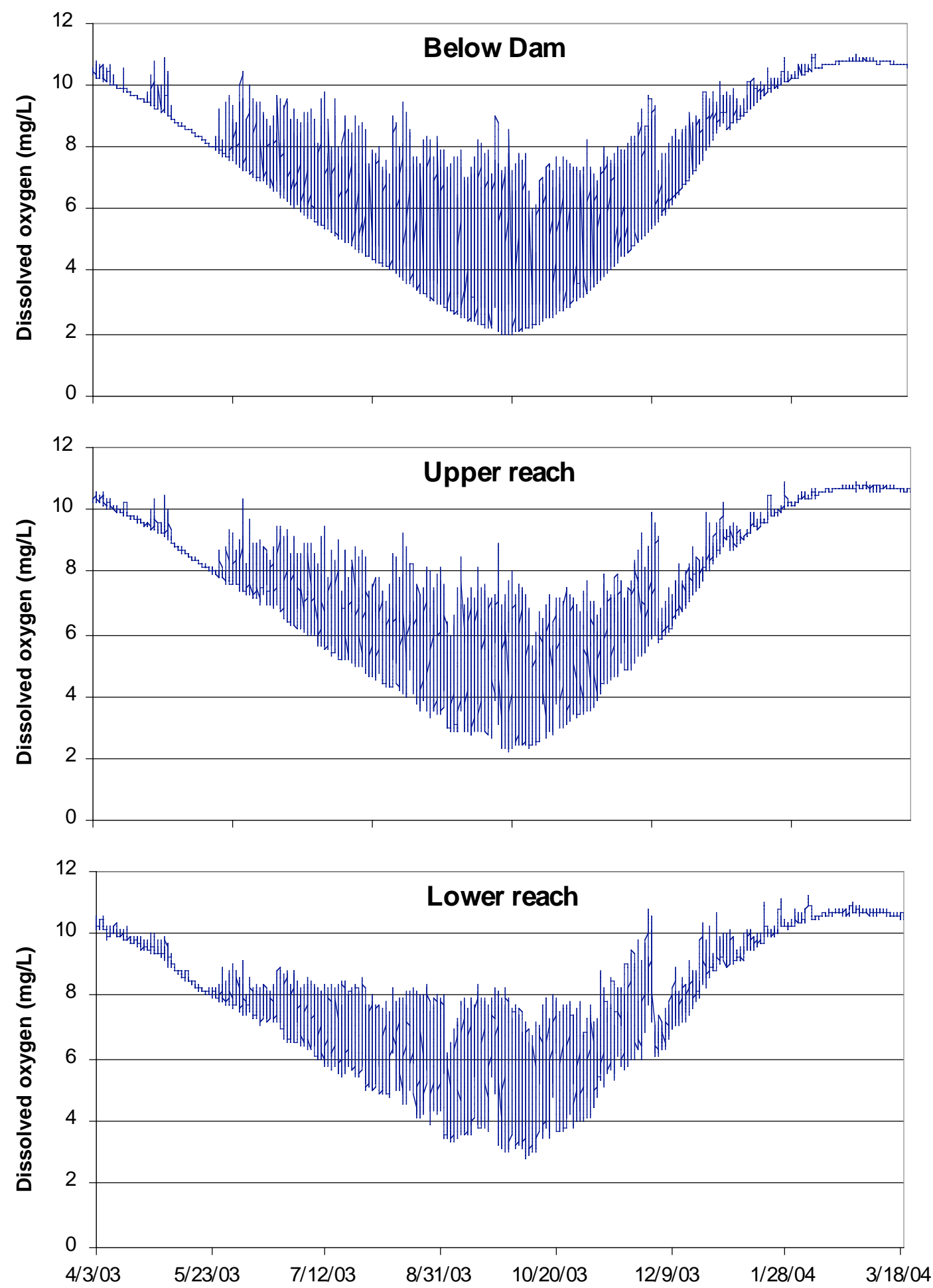

Fig. 3.2. Model generated temporal profile of hourly dissolved oxygen for three reaches below Center Hill Dam under baseline conditions. 

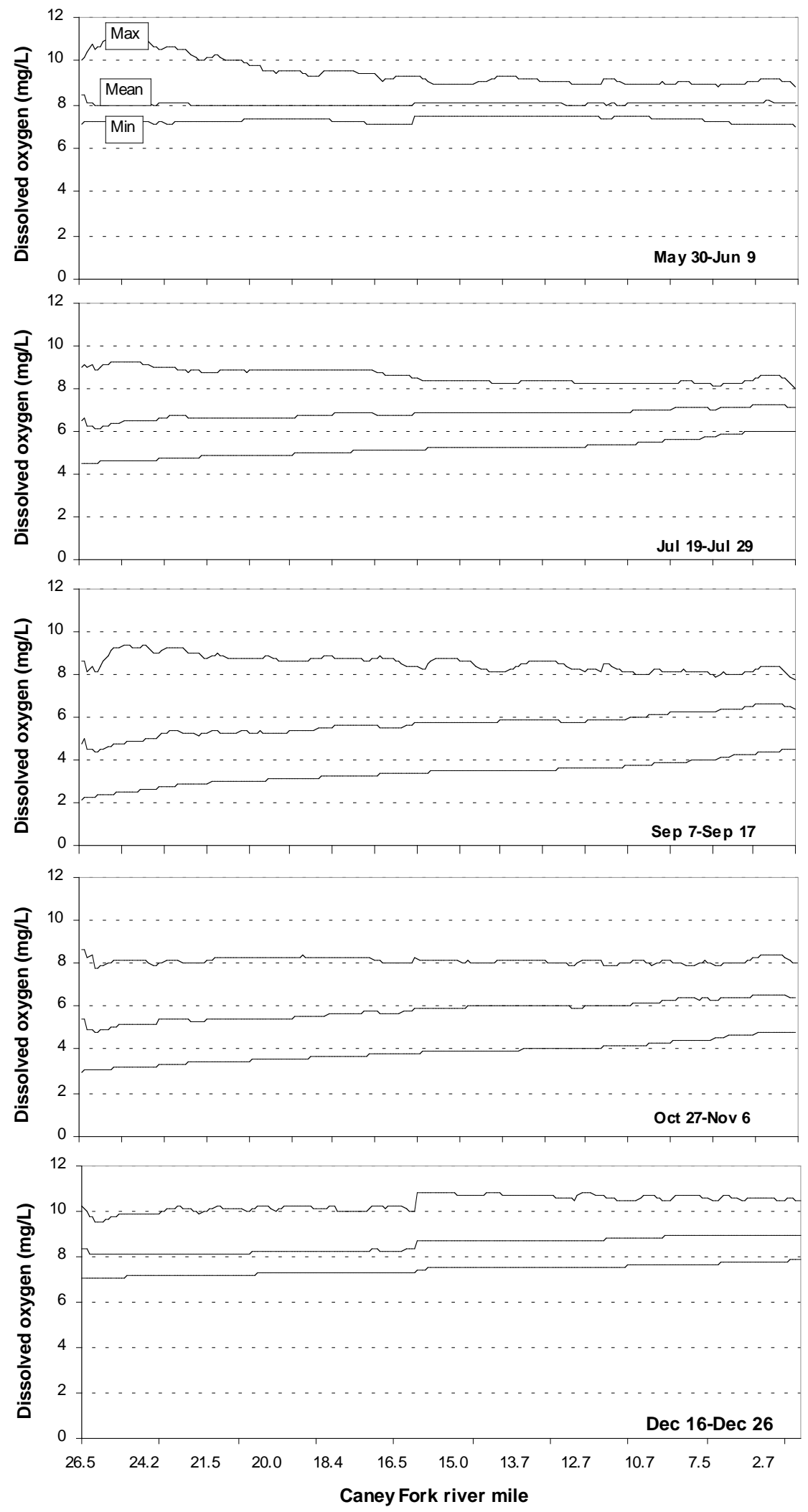

Fig. 3.3. Maximum, mean, and minimum dissolved oxygen concentration over the entire 26.5 mile tailwater during five $\mathbf{1 0}$-day periods. 


\subsubsection{Fish Growth}

The main objective in calibration of the fish growth model was to create a general match between predicted growth and observed growth throughout the first 14 miles below the dam, the portion of the river sampled in 2003-04. We simulated growth for three river reaches simultaneously. Our goal in calibration was to achieve simulated growth for the three reaches that fit as well as possible into the range of observed weights. The three reaches used for calibration and subsequent analyses were: 1) immediately Below Dam - RM 26.5-25.5; 2) Upper half of managed reach - RM 26.5-19.5; and 3) Lower half of managed reach - RM 19.5-12.5. The model computes growth in the reach based on spatial averaging of temperature and DO over the reach at each time step. Thus, the modeled growth for a reach more or less represents the midpoint of the defined reach. Midpoints for the three reaches are RM 26.0, RM 23.0, and RM 16.0.

Starting with input parameters from the Loginetics study, we only had to make slight adjustments in the general food consumption rate to produce a general match to observed weights (Fig. 3.4). As with the observed data, the simulations indicate a slow growth period during summer months when water temperatures are highest and DO levels are lowest.

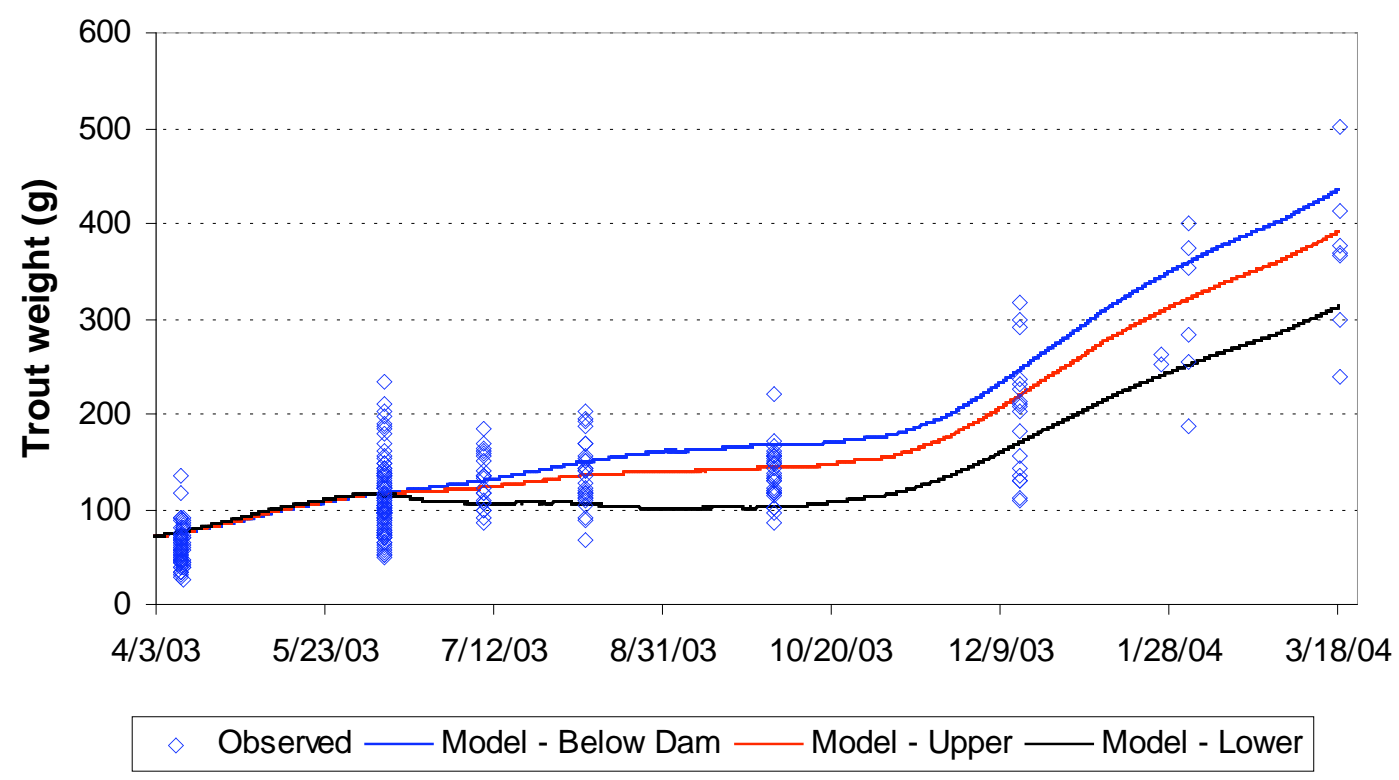

Fig. 3.4. Calibrated model predictions of brown trout weight during the course of the simulation for three river reaches (lines) compared to observed weights of individual trout (diamonds).

Because the number of fish captured from April 2003 to April 2004 at each sampling location was not consistent (and often quite low), we did not calibrate to mean values for specific reaches of the river. However, we did evaluate whether model predictions followed the same general trends as seen in the field data for the Upper and Lower reaches. Without any additional calibration, simulations for both Upper and Lower reaches were compared to the observed weights from sampling sites that correspond to our definitions of Upper and Lower reaches (Fig. 3.5 and Fig. 3.6). In both cases, the simulated growth generally tracks the distribution of observed values. 


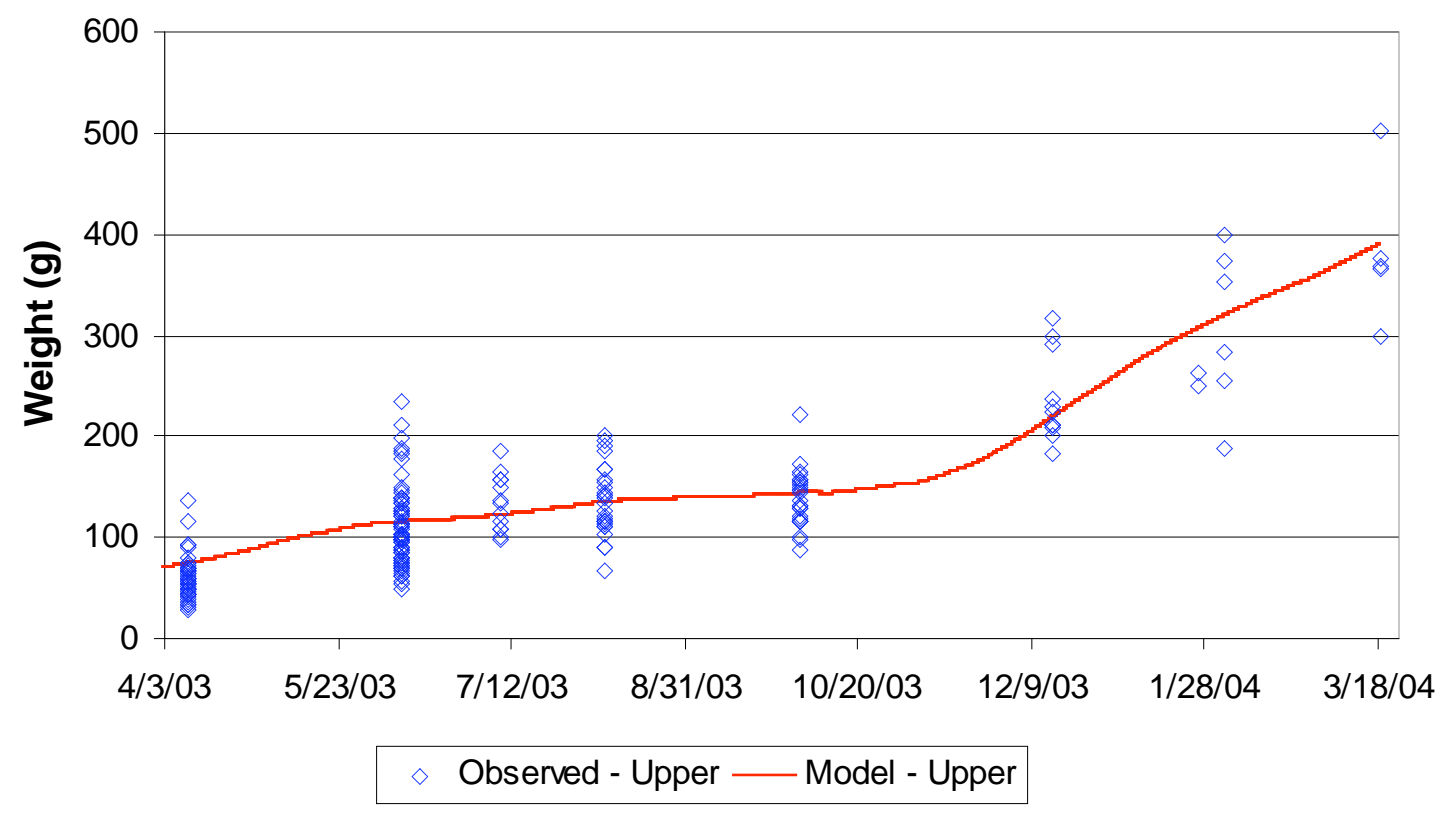

Fig. 3.5. Model prediction of brown trout growth in the Upper reach compared to observed weights from fish captured from sample sites in the same reach.

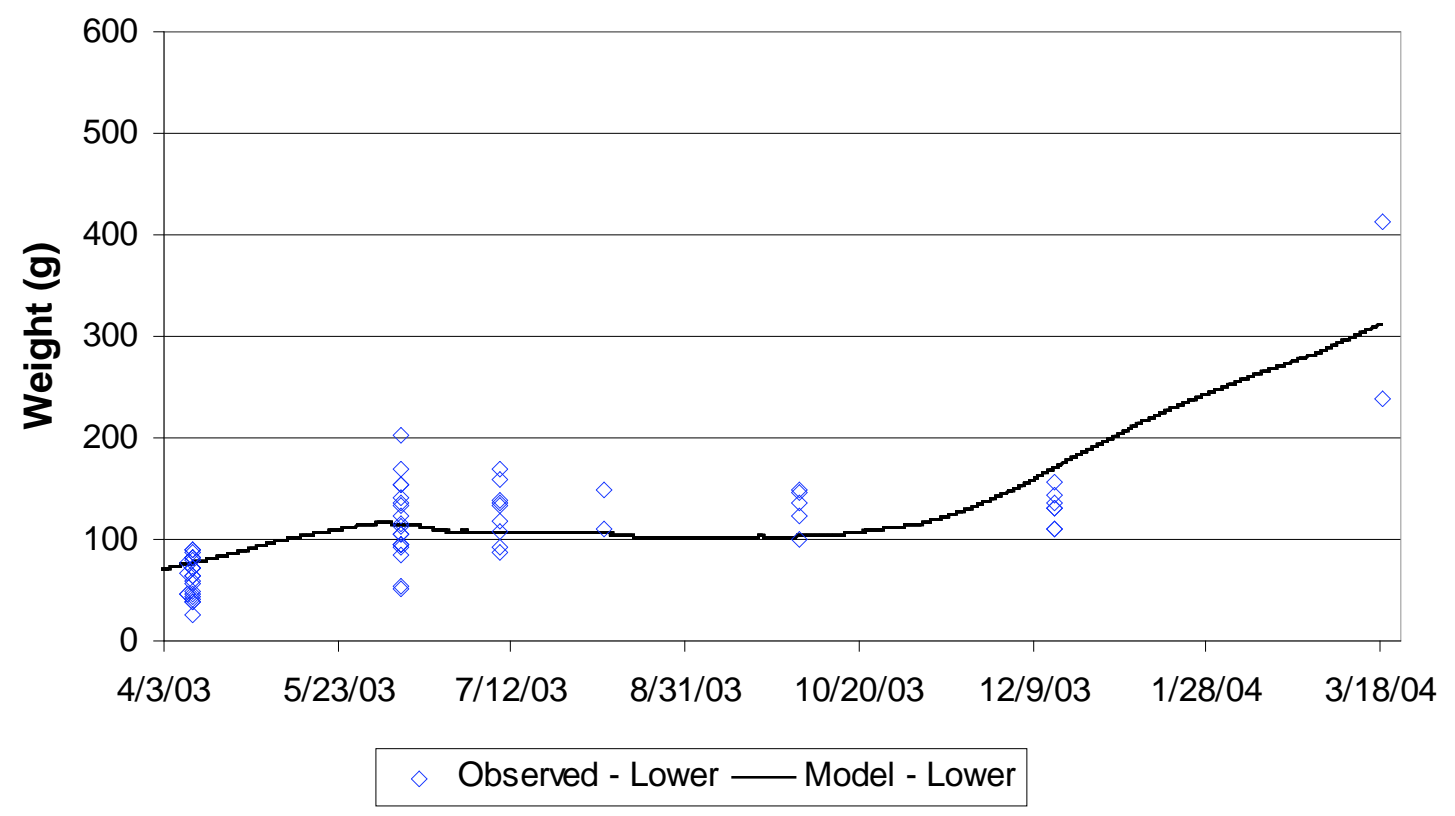

Fig. 3.6. Model prediction of brown trout growth in the Lower reach compared to observed weights from fish captured from sample sites in the same reach. 
An unexpected result of the baseline simulation was higher predicted growth at reaches nearer the dam (see Fig. 3.4). A similar outcome is suggested in the comparison of observed values (see Fig. 2.2). The only input variables that affect modeled fish growth that are not equal among reaches are temperature and DO. Because DO increases as one gets farther from the dam, we can conclude that the reason that the Lower reach has reduced growth is largely a function of higher temperatures downstream.

To better understand the effect of low DO on growth under baseline conditions, we performed an additional simulation where the DO effect on food consumption (and therefore growth) was removed from the model. Because other factors are also constant, the resulting differences in growth are entirely a function of temperature (Fig. 3.7). With the DO effect removed, trout at the Below Dam site would be expected to exhibit the greatest growth rates.

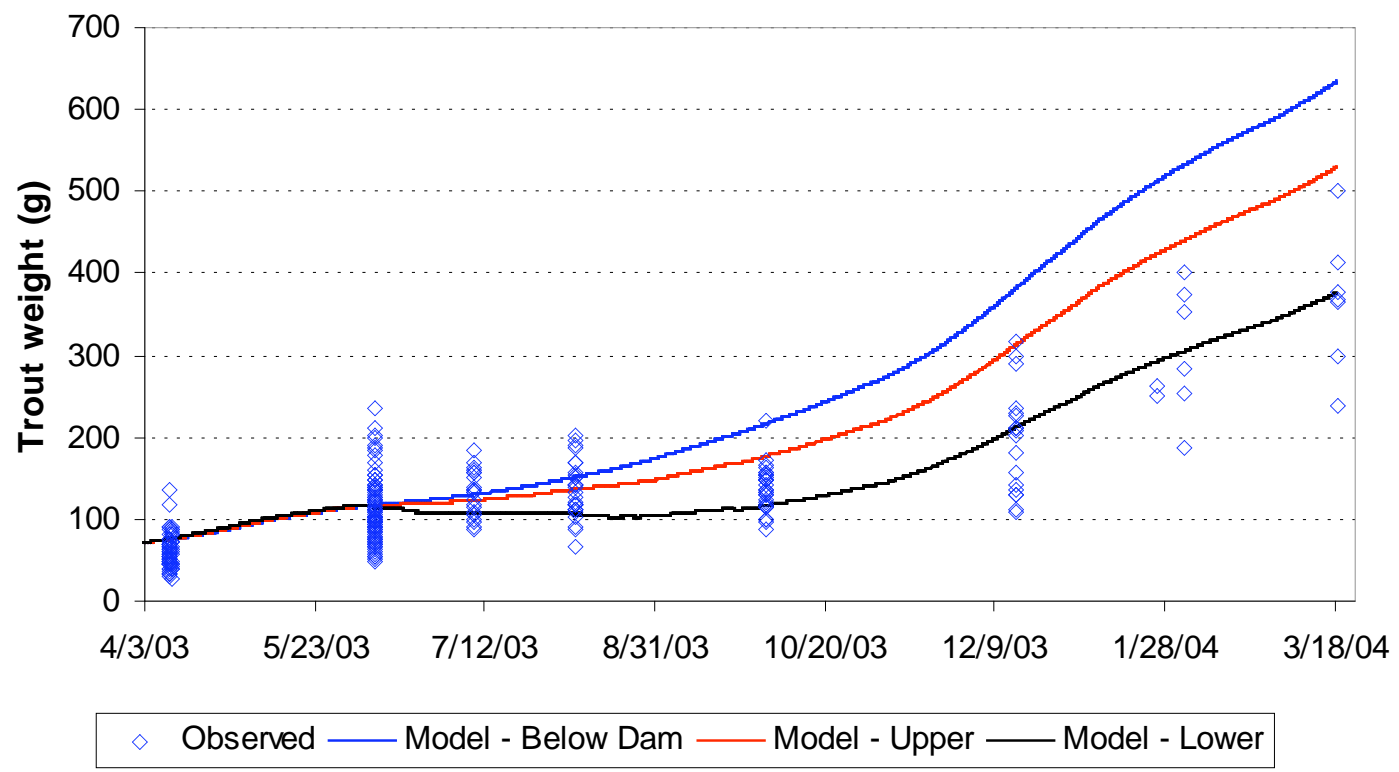

Fig. 3.7. Model simulated growth of trout in three reaches below Center Hill Dam with DO effects turned off.

\subsection{SIMULATED BENEFITS OF TURBINE AERATION}

Mitigation to increase DO in the vicinity of the turbine can take place by a variety of methods as described earlier in this report. Some of these methods, such as nosecone venting, are permanent fixes that can not be turned on or off and would likely provide some benefit at all times - more so when the ambient DO is very low. Other methods, such as forced aeration of the turbine, would likely be implemented such that they could be turned on when needed and off when ambient DO was sufficiently high. The simulations we performed are more like the latter. For example, in the simulation where we simulated a minimum DO of $3 \mathrm{mg} / \mathrm{L}$, the DO from the dam (i.e., turbine outfall) was set at $3 \mathrm{mg} / \mathrm{L}$ whenever the DO in our baseline input was less than $3 \mathrm{mg} / \mathrm{L}$. When ambient DO exceeded $3 \mathrm{mg} / \mathrm{L}$ no change was made. In reality, most turbine aeration technologies are not this precise in their control, and would likely have more variable effect on the release DO. Although we did not simulate the case of a method that is continuously operational, such simulations would only require a slightly different algorithm for estimating improved DO levels 


\subsubsection{Water Quality}

Simulated improvements in DO at the dam result in increased DO levels throughout the river. Figure 3.8 shows the results of simulating DO improvement like that indicated in Fig. 2.13 on downstream DO (see Fig. 2.15 for comparison to the baseline simulation). Another way to view the effects of the simulated DO improvements on downstream DO is by looking at minimum-maximum envelopes that describe the range of DO over a short period of time across the entire length of the tailwater. Such envelopes are illustrated in Fig. 3.8 and Fig. 3.9 for improvements to 4 and $6 \mathrm{mg} / \mathrm{L}$, respectively, for three time periods each. When the release DO is improved to $4 \mathrm{mg} / \mathrm{L}$, there is a large increase in minimum DO for the September and October periods, a small increase in mean DO, and no increase in the maximum. The simulations of increasing release DO to $6 \mathrm{mg} / \mathrm{L}$ raised the minimum and mean throughout the river for all three periods; maximum values increased slightly. 

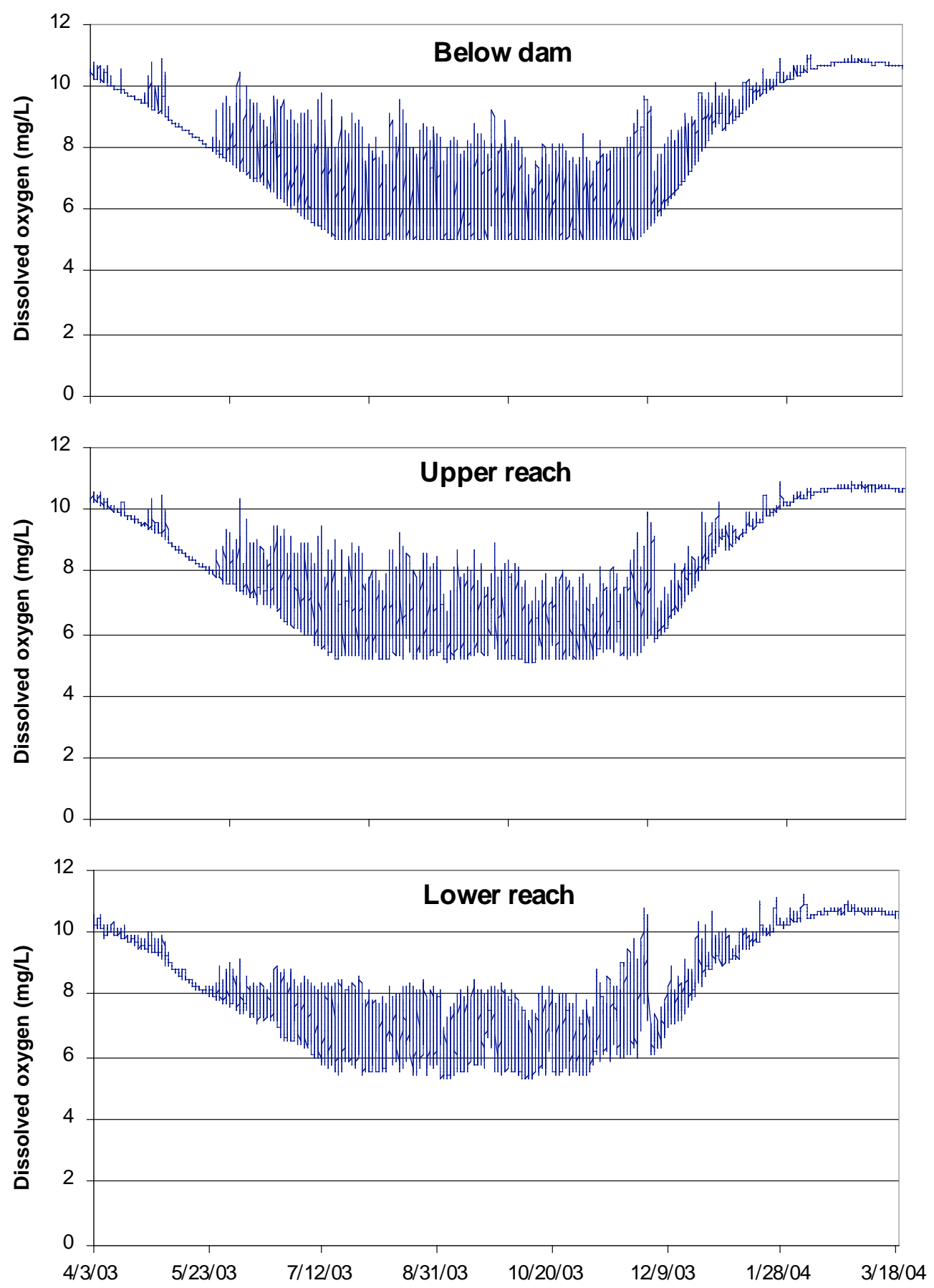

Fig. 3.8. Model-simulated hourly DO at three locations in the Caney Fork River when dam release limited to a minimum DO of $5 \mathrm{mg} / \mathrm{L}$. 

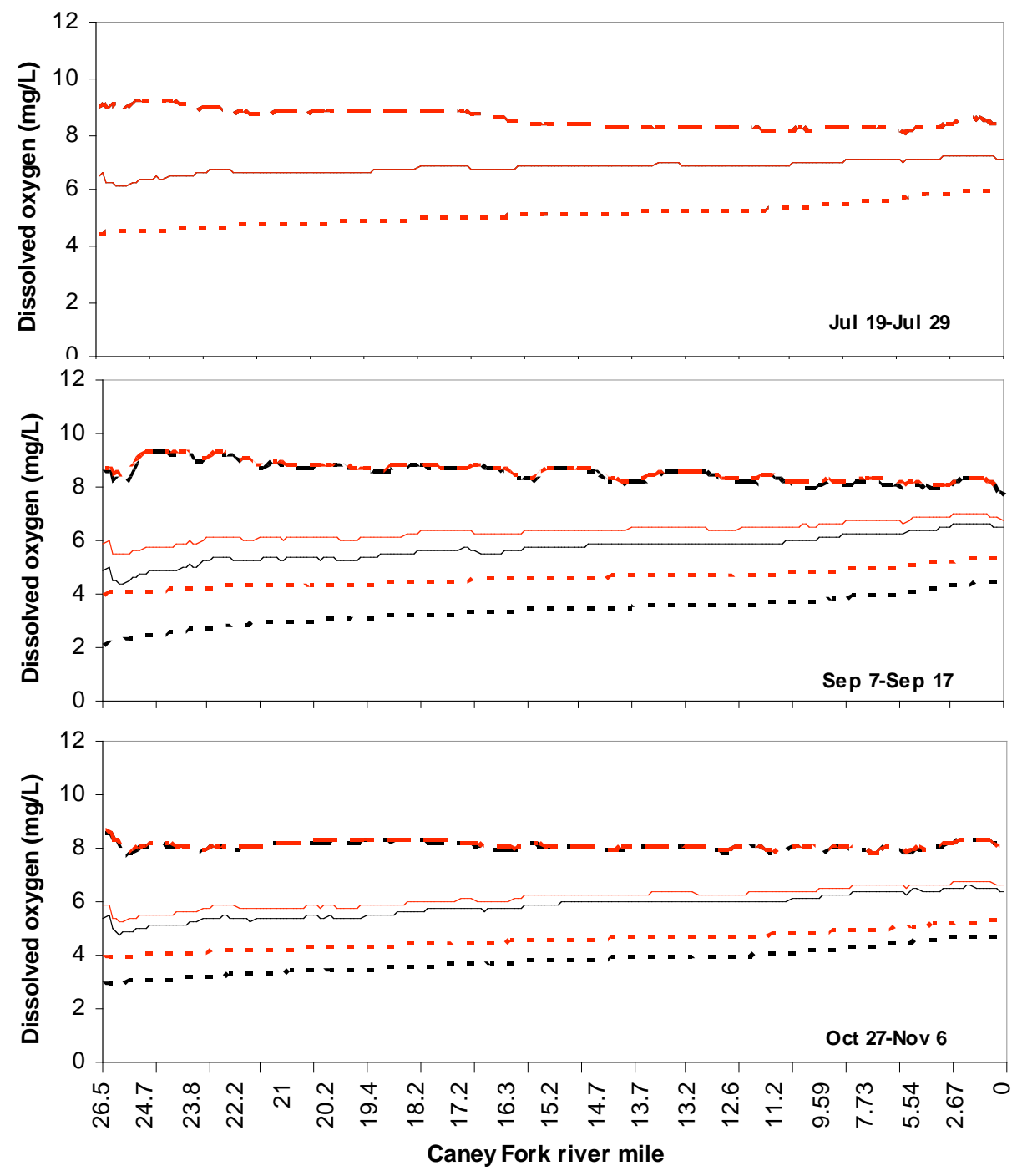

Fig. 3.9. Maximum (dashed), mean (solid), and minimum (dotted) dissolved oxygen levels in the Caney Fork River for three periods during a simulated mitigation (red lines) that improved DO in dam releases to $4 \mathrm{mg} / \mathrm{L}$. The baseline simulation (black lines) is included for comparison. (Note: in the top panel, the baseline and improved simulations are identical) 

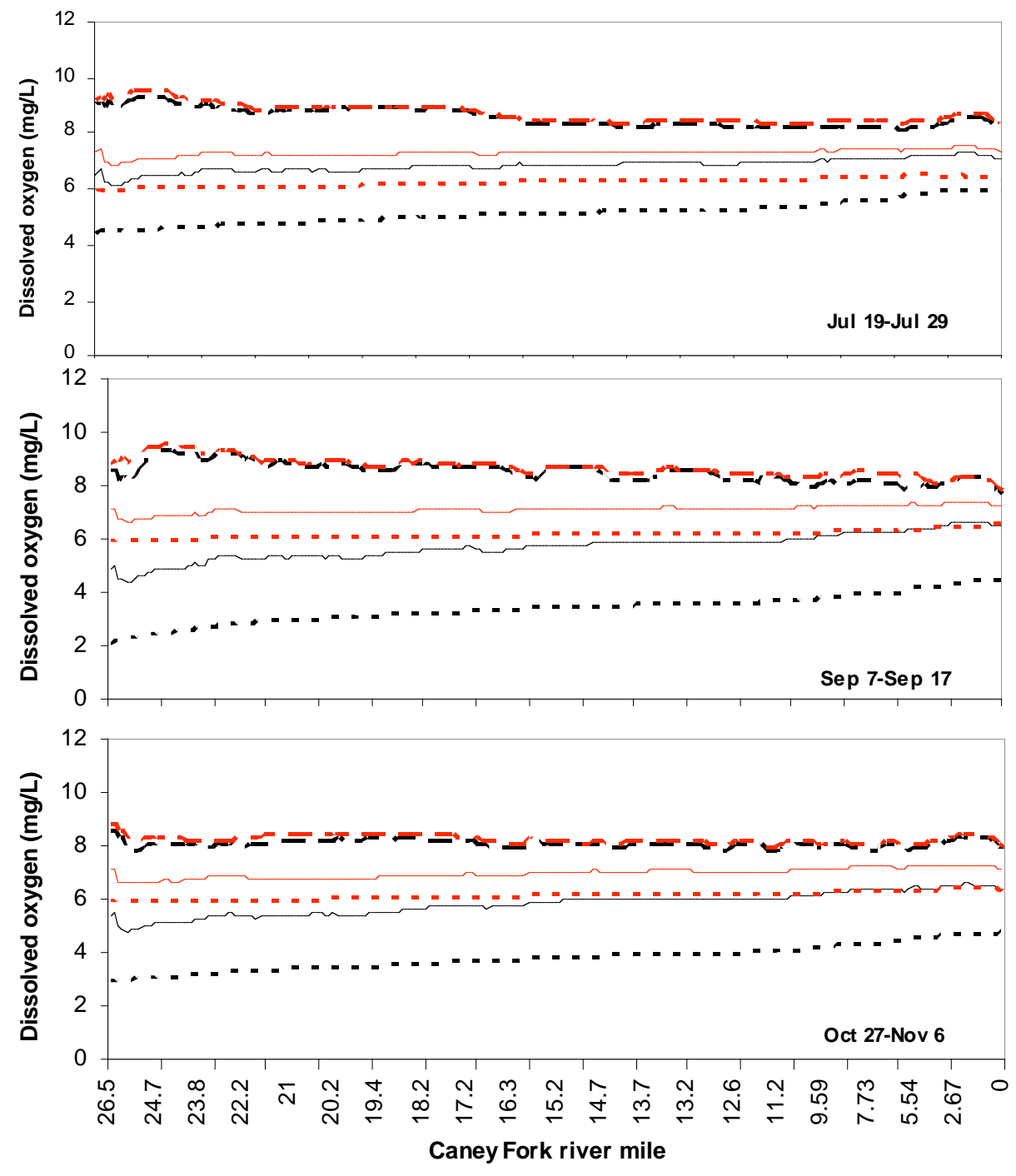

Fig. 3.10. Maximum (dashed), mean (solid), and minimum (dotted) dissolved oxygen levels in the Caney Fork River for three periods during a simulated mitigation (red lines) that improved DO in dam releases to $6 \mathrm{mg} / \mathrm{L}$. The baseline simulation (black lines) is included for comparison.

\subsubsection{Fish Growth}

Fish growth improved throughout the river under simulated conditions with minimum DO levels of 3, 4, 5, or $6 \mathrm{mg} / \mathrm{L}$ relative to baseline conditions (Fig. 3.11). As expected final trout size increased with increasing DO. The greatest improvement in growth (nearly $50 \%$ increase) occurred at the Below Dam site and the least (about 25\% increase) occurred at the Lower reach. The outcome of greater response to improved DO at the upstream sites was largely a function of the amount of increase in DO as a result of the simulated mitigation combined with the more favorable temperatures for growth near the dam. Because DO levels were generally lower just below the dam, the absolute increase in DO for those days when DO was increased was usually larger at the upstream sites. It is obvious by the difference in the amount of spread in the lines within each reach that the biological response per unit of DO improvement was greatest at the most upstream reach. 

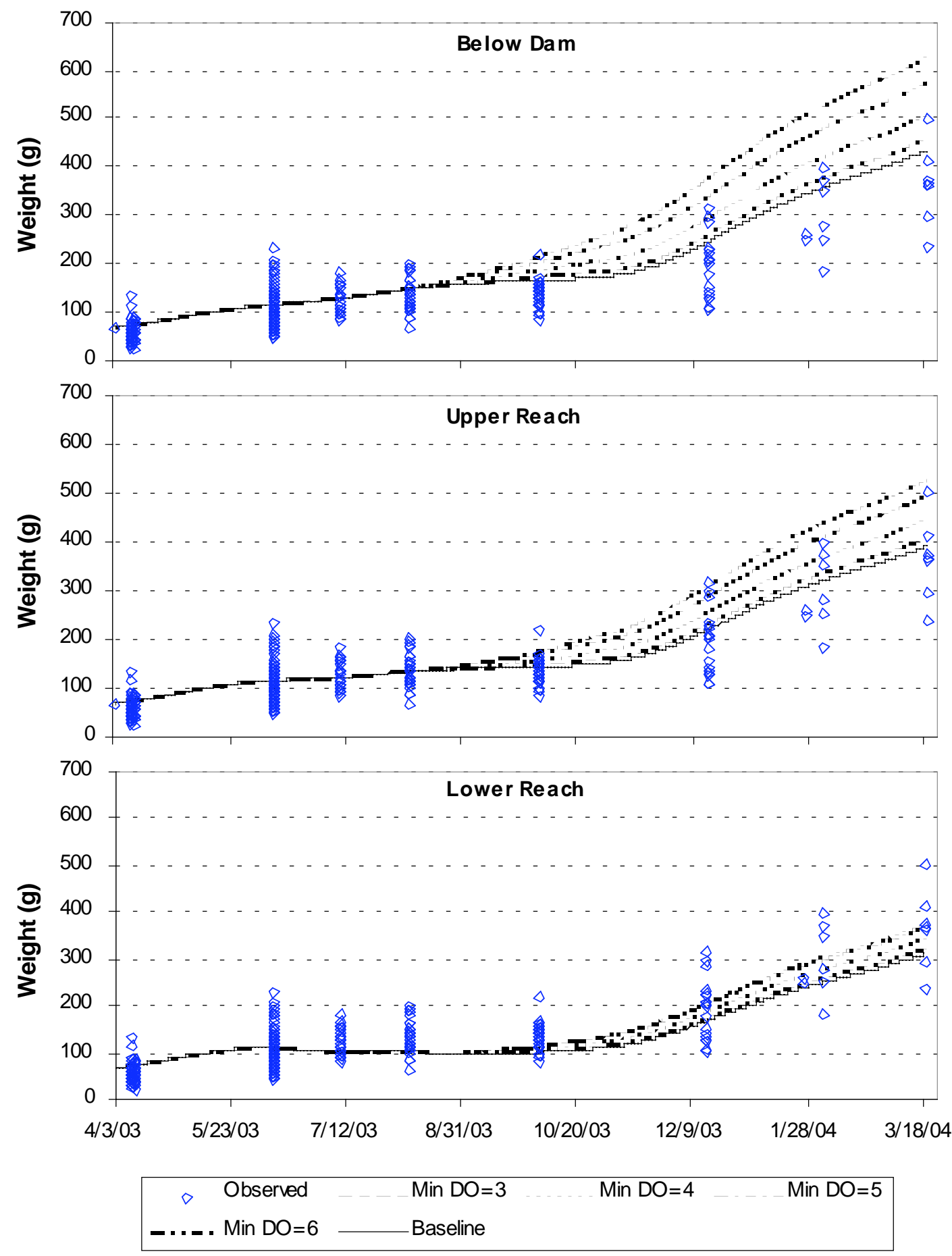

Fig. 3.11. Simulated trout growth under conditions of incremental improvements in DO at three reaches of the Caney Fork River below Center Hill Dam. In all cases the top line represents improvement to $6 \mathrm{mg} / \mathrm{L}$, the next line to $5 \mathrm{mg} / \mathrm{L}$, and so on. 


\subsection{SIMULATED BENEFITS OF FOREBAY AERATION}

Several types of DO mitigation can be implemented in the forebay (i.e., in the reservoir before water enters the turbine), such as forebay mixing, surface water pumps, flexible curtains, forebay aeration/oxygenation, or multiple or variable intake locations. All of these measures except for forebay aeration/oxygenation with line diffusers (low upwelling) are likely to result in increased release temperatures as well as increased DO levels. Some mechanical methods (i.e., mixing fans or pumps) are designed to purposefully mix cooler oxygen-poor hypolimnetic (or bottom) waters with warmer oxygen-rich epilimnetic (or surface) waters. Variable depth intake structures would also draw in warmer oxygen-rich waters into the turbines.

Aeration of the forebay by bubbling air or oxygen from the bottom can mix cooler and warmer water, but some have found that oxygen line diffusers often have no effect on forebay thermal profiles or release temperatures due to the low upwelling and high gas transfer efficiencies (G. Hauser, personal communication). Depending on the level of the intakes, bubbling air in the forebay aeration can cool or warm releases as cold water is upwelled. Air bubblers have sometimes been used to cool releases (by mixing cold hypolimnetic water to mid- or high-level intakes).

To demonstrate how the model can be used to simulate these types of mitigation, we provide an example where minimum DO is set at $5 \mathrm{mg} / \mathrm{L}$ and temperature is increased by $3^{\circ} \mathrm{C}$. This is a conservative estimate of the amount of temperature increase, as temperature increases would likely be greater than this for many cases.

\subsubsection{Water Quality}

Improvements in DO under the conditions simulated (i.e., dam release DO increased to $5 \mathrm{mg} / \mathrm{L}$ ) produce results that are intermediate to those illustrated in Fig. 3.1.2 and Fig. 3.1.3 with improvements to 4 and $6 \mathrm{mg} / \mathrm{L}$, respectively. Of greater interest is to what extent the $3^{\circ} \mathrm{C}$ increase in release temperature affects temperature throughout the rest of the river (Fig. 3.1.2). During the three periods shown in the figure, an increase of $3^{\circ} \mathrm{C}$ at the dam resulted in a mean increase in temperature throughout the river of $2.6-2.7^{\circ} \mathrm{C}$. The average maximum values throughout the river increased by 2.0-2. $4^{\circ} \mathrm{C}$. The absolute maximum values occurred in the upper 5 miles of the tailwater and exceeded 25 and $24^{\circ} \mathrm{C}$ in the late July and early September periods, respectively. 

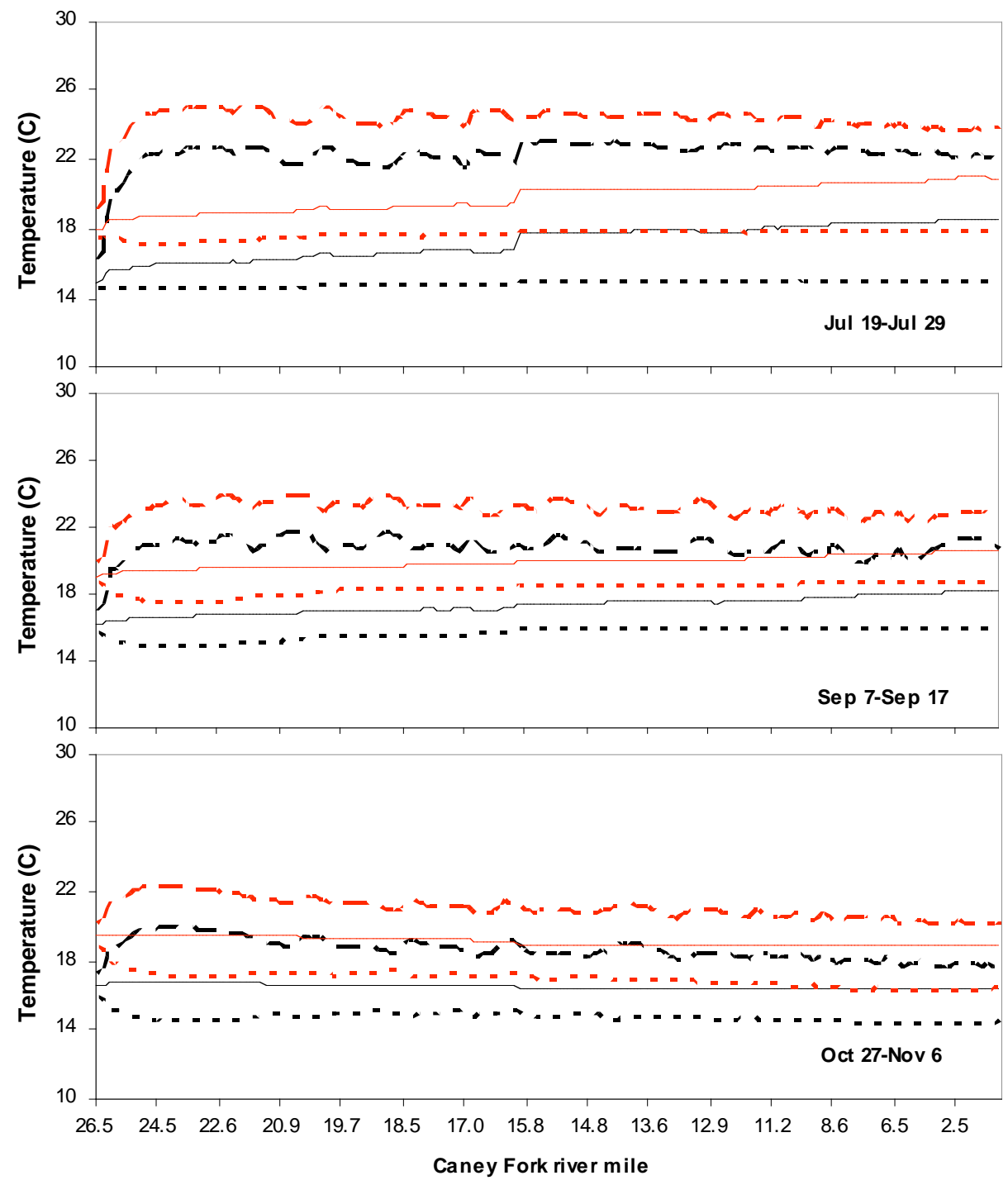

Fig. 3.12. Maximum (dashed), mean (solid), and minimum (dotted) temperatures in the Caney Fork River for three periods during a simulated mitigation (red lines) that improved DO in dam releases to 5 $\mathbf{m g} / \mathrm{L}$, but also increased temperature by $3^{\circ} \mathrm{C}$. The baseline simulation (black lines) is included for comparison.

\subsubsection{Fish Growth}

The effects of increased DO accompanied by increased temperature has an overall negative impact on fish growth at the levels modeled here (Fig. 3.13) For the Center Hill tailwaters, the negative effect of increased temperature far outweighs the positive effect of improved DO. Of course, every system is different and whether or not the combined effect is negative or positive depends on several factors including the degree of warming and the thermal requirements of the species present. Brown trout in the Caney Fork River are already at or above the optimum temperature for growth in the summer. Our model predicts that decreasing DO concentrations at the cost of further increasing summer water temperatures would have a detrimental effect on brown trout growth. 


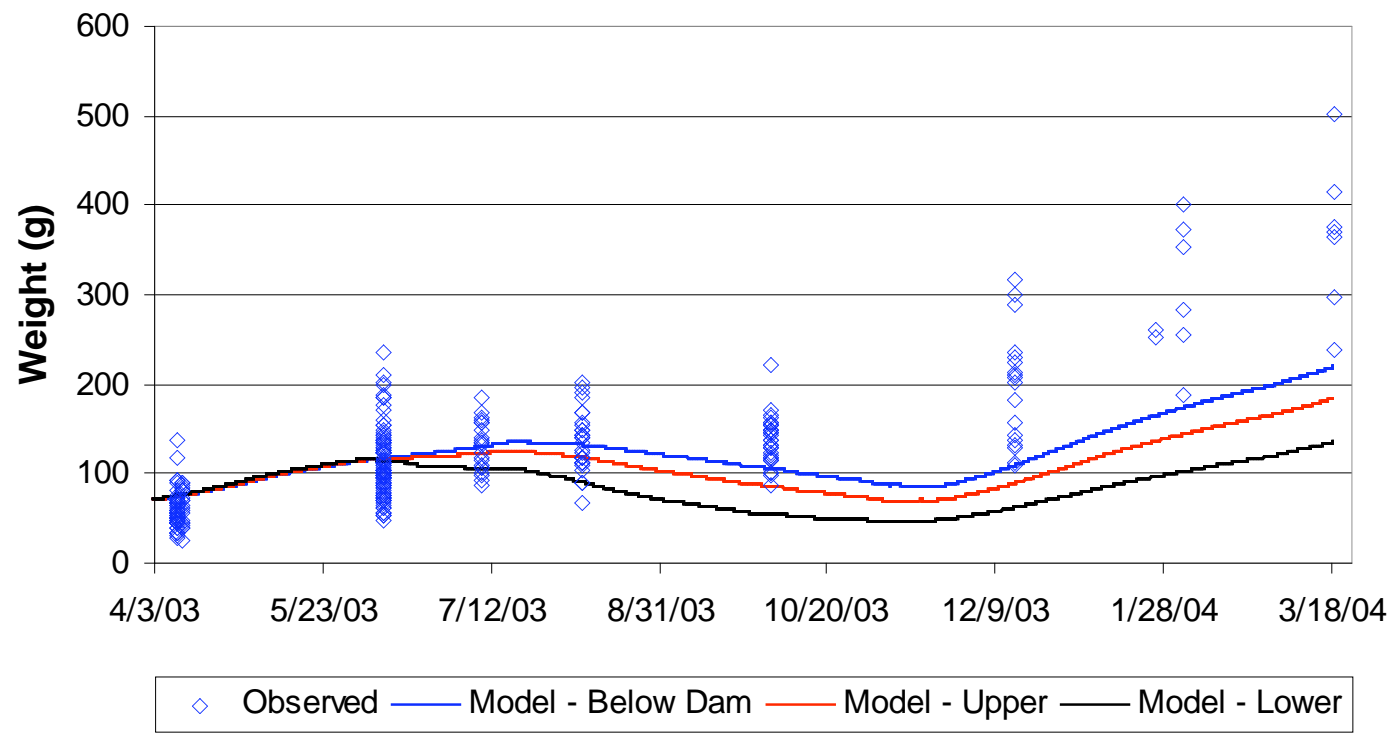

Fig. 3.13. Simulated trout growth under conditions of increased DO and increased temperature at three reaches of the Caney Fork River below Center Hill Dam as might be expected from mixing surface waters to increase DO. 


\section{DISCUSSION}

The main objective of this study was to evaluate a modeling approach that combines models of flow and water quality dynamics with fish bioenergetics for the assessment of the effectiveness of dissolved oxygen mitigation. We were particularly interested in demonstrating the benefits of including the fish growth model as a measure of biological response. The usefulness of hydrodynamic and water quality models have been demonstrated many times by other investigators, but including a fish bioenergetics model to assess hydropower operations is still a developing technology.

In our opinion, the model performed very well in simulating the existing system. After only limited calibration, the model predicted growth dynamics that were very similar to those observed, including differences in growth rates among reaches. Had more fish been collected during field sampling which would have provided a better understanding of the spatial and temporal dynamics of growth, the model could have been calibrated with even greater accuracy.

The fish bioenergetics model contains more uncertainty than the hydrodynamic and water quality models and could still benefit from additional testing and revision. For example, fisheries biologists have known for many years that low DO levels often result in lower food consumption rates and lower growth rates, but the mechanisms are complex and difficult to model. Instead of the simple DO-to-appetite-suppression model used here (see Fig. 2.12), a more mechanistic approach to the effects of low DO would greatly improve the model. Another potential improvement to the current approach would be to provide a direct link in the model between environmental conditions and the abundance or quality of the food resource. The model does allow for seasonal adjustments in food consumption that could be used to simulate variable food availability, but including water quality effects on other components of the aquatic community could be useful for some situations.

The model does not account for the possibility that where a fish is captured may not accurately reflect the conditions it has experienced during the simulation period. Several studies have documented how the movements of fish are often driven by DO, temperature, and food availability and how growth is then affected by habitat choice (Coutant 1985, Bettoli 2005). If the favorability of habitats varies longitudinally throughout the Caney Fork, then we might expect movements by trout that reflect that. These are both issues that can be explored by the model system used in this study.

One aspect of hydropower operations that has not been adequately addressed is the effects of intermittent exposure to low DO or high temperature. Because of the peaking (or pulsing) nature of many hydropower operations, many aspects of water flow and quality fluctuate significantly over the course of a day. Too few experimental studies on how fish respond to such conditions have been done to develop a consensus on a standard response. Stewart et al. (1967) and Whitworth (1968) both found that fish exposed to intermittently low and high DO had lower growth rates than fish exposed to the mean DO concentration. A review of the subject by Brett (1979) concludes that exposure to sub-critical DO levels for only a portion of the day is enough to depress the growth rate to that comparable with the constant low DO concentration. For example, does a fish exposed to low DO for half the day and high DO for the other half respond 1) as if it were exposed to the mean level all day, 2 ) as if it were exposed to the lowest level all day, or 3) to each half of the day differently? In our simulations, fish respond each hour to the conditions as encountered regardless of the prior thermal history or any possible negative effects of rapid change. Being able to include a more accurate response to fluctuating conditions in the model would greatly improve its capabilities.

The simulations we performed in this study looked at the effects of changes in water quality released from the dam on downstream fish growth. This kind of analysis would be useful in formulating recommendations for possible mitigation. Tables 1 and 2 include examples of different types of DO mitigation and the levels of improvement that were realized at specific applications. Results from modeling can be used to determine what kind of and how much improvement must be 
attained at the dam to meet specific mitigation targets (e.g., downstream DO levels or improvements in fish growth). The choice of mitigation techniques can then be narrowed based on the ability of various techniques to achieve the targeted dam improvement based on summaries like that in Tables 1 and 2 .

The model is particularly useful for evaluating how much improvement in water quality or biological response is attained with each subsequent unit of improvement at the dam. For example, being able to predict when returns on improvement begin to diminish is crucial to producing costeffective mitigation. Unfortunately, the point of diminishing return is site-specific and depends on a variety of factors, which is why the modeling approach is so attractive.

Center Hill Dam was chosen as a demonstration project because we were able to build off of an existing model and not because we had specific objectives related to Center Hill operations. However, we can still provide observations based on model results that might aid future decisions to improve DO in the Center Hill tailwaters. Center Hill turbines have been modified once with the addition of turbine venting, but the amount of improvement is relatively small and does not prevent dam releases from being below $5 \mathrm{mg} / \mathrm{L}$ for several weeks each year. Other techniques or improvements to the venting will probably be necessary to make significant improvements in DO. Our modeling suggests that improvements in the forebay may be counterproductive toward the goal of increasing brown trout growth if they also result in elevated temperatures. Because conditions of low DO in the immediate tailwaters below the dam seem to persist throughout the river, techniques that would contribute to aeration in the river itself should be considered. Small weirs that contribute to aeration, but don't create oxygen-depleting pools could improve DO throughout the river if placed in the right places.

The impact of poor water quality in the Center Hill tailwaters may be a contributor to the low survival of stocked trout observed there (Meerbeek 2005). Our modeling suggests that high temperatures as well as low DO are significant contributors to low growth at certain times of the year, which could lead to greater susceptibility to disease and predation. Any DO mitigation that maintains or, even better, decreases release temperatures should be strongly considered. The modeling results also suggest that the conditions in Caney Fork probably push the thermal and DO limits for the coldwater species stocked there. Neither brown trout nor rainbow trout are native to the Caney Fork River and perhaps along with mitigation to improve water quality, resource managers should consider managing for other species that are not as sensitive to elevated temperature and low DO.

The value of any model is often measured by its transferability to systems other than those where it was developed. The combination of models used in this exercise has been successfully used at a variety of sites throughout the country, particularly the hydrodynamic and water quality components. Each use of the model requires some significant setup time to incorporate site-specific information on the physical parameters of the river system, local environmental conditions, river hydrology, and water quality. Calibration requires additional time plus some expertise and fairly thorough knowledge of the models and their underlying equations. Almost anyone with some modeling acumen could learn (or more appropriately be trained) to use the model over several months time. The model system is too complicated for someone to just pick it up and start using it. However, after a calibrated model is obtained, making further changes to simulate different scenarios is fairly straightforward. Nearly anyone can use the included graphics manager to visualize results in a variety of ways.

Although the inner workings of the model are quite complex, using it to evaluate DO mitigation is fairly straightforward. The three major types of DO mitigation as defined by where the effective action takes place (see Table 1) each can be evaluated in their own way with the model. 
1) Turbine - Manipulations at the turbine (e.g., turbine venting, air injection, and draft tube venting) typically affect DO levels, with little change in temperature or other water quality parameters. Modeling these enhancements usually requires changing the hourly DO in a single input file to reflect higher levels being released from the dam. Comparisons of different levels of improvement like those described earlier in this report are easily simulated. For systems with multiple units, evaluating the relative gains of retrofitting one or several turbines is fairly straightforward if one knows the relative contribution in DO improvement of each additional turbine that is modified or replaced.

2) Forebay - Manipulations in the forebay (e.g., recirculating pumps, flexible curtains, and variable depth intakes) typically result in a change in both DO and temperature in water passed through the turbines. These changes are easily simulated by changing the hourly temperature and DO values in the water quality boundary conditions for the node at the release point (i.e., the dam). It may be necessary to change NBOD and CBOD values as well. A simple first cut simulation might include a constant change in DO and temperature (like presented in this report), whereas a more detailed investigation might also include using the results of a reservoir water quality model to more accurately estimate changes in forebay DO and temperature over a long period.

3) Downstream - Downstream changes are a little less straightforward depending on the type of mitigation. Any physical changes to the river (e.g., re-aeration weirs) would need to be captured as an internal boundary condition or in the river geometry information in the hydrodynamic model. The effects of these changes (e.g., re-aeration at a cascade or temperature changes in new pools) would automatically transfer to calculations in the water quality model. Other types of tailwater mitigation (such as air injection to the stream or a tributary) would require changing the DO at a lateral inflow. The existing modeling system used in this investigation is capable of these kinds of simulations.

In all cases, the accuracy of a model depends on the accuracy of the model mechanisms, the accuracy of the input data, and the accuracy of those data used for calibration. The hydrodynamic and water quality models are based on physical laws and properties that are well-understood. These models have been successfully tested and applied several times. The underlying mechanisms and principles of the fish growth model have been applied to answer a variety of questions, but still require further development, especially with regard to the fluctuating conditions that are present in many hydropower systems. At the current stage of development, the fish growth model still can provide valuable insight into the effectiveness of DO mitigation as long as the user understands and communicates underlying assumptions and uncertainties. 


\section{REFERENCES}

Adams, S. M., and J. E. Breck. 1990. Bioenergetics. Pages 389-415 in C. B. Schreck and P. B. Moyle, editors. Methods for fish biology. American Fisheries Society, Bethesda, Maryland.

Bettoli, P. W. 2005. The fundamental thermal niche of adult landlocked striped bass. Transactions of the American Fisheries Society 134:305-314.

Bevelhimer, M., V. Alavian, B. Miller, and G. Hauser. 1997. Modeling Thermal Effects of Operational and Structural Modifications at a Hydropower Facility on a Premier Trout Stream in Southwestern Montana. Water Power 97 Proceedings.

Brett, J. R. R. 1979. Environmental factors and growth. Pages 599-675 in W. S. Hoar, D. J. Randall, and J. R. Brett, editors. Fish Physiology - Volume VIII: Bioenergetics and Growth. Academic Press. New York.

Carter, J., Jr. 1995. Recent experience with turbine venting at TVA. Pages 1396-1405 in J. J. Cassidy, editor. ASCE Proceedings of the International Conference on Hydro Power: WaterPower '95. American Society of Civil Engineers, New York.

Coutant, C. C. 1985. Striped bass, temperature and dissolved oxygen: a speculative hypothesis for environmental risk. Transactions of the American Fisheries Society 114:31-61.

Elliot, J. M. 1976. The energetics of feeding, metabolism, and growth of brown trout (Salmo trutta L.) in relation to body weight, water temperature and ration size. Journal of Animal Ecology 45:923-948.

EPA (U. S. Environmental Protection Agency). 1986. Ambient water quality criteria for dissolved oxygen. EPA 440/5-86-003. Office of Water, Criteria and Standards Division, Washington, DC.

EPRI (Electric Power Research Institute). 1992. Maintaining and monitoring dissolved oxygen at hydroelectric projects: status report. Report 1005194. Palo Alto, California.

EPRI. 1996. Aerating weir design. Technical Report TR-103947, Palo Alto, California.

EPRI. 2002. Maintaining and monitoring dissolved oxygen at hydroelectric projects. Status report. Technical Report 1005194, Palo Alto, California.

Gaffney, S. R., T. A. Jablonski, and J. Kirejczyk. 1999. Using hydro turbines to enhance dissolved oxygen levels. Hydro Review, August.

Garton, J. E., and R. Miller. 1982. Dissolved oxygen improvement by local mixing. Article J-4043, Oklahoma Agriculture Experiment Station.

Harshbarger, E. D., B. Herrold, G. Robbins, and J. C. Carter. 1998. Turbine venting for dissolved oxygen improvements at Bull Shoals, Norfolk, and Table Rock dams. HydroPower '98. HCI Publications, Kansas City, Missouri. 
Harshbarger, E. D., M. H. Mobley, and W. G. Brock. 1995. Aeration of hydroturbine discharges at Tims Ford Dam. Pages 11-19 in J. J. Cassidy, editor. ASCE Proceedings of the International Conference on Hydro Power: WaterPower '95. American Society of Civil Engineers, New York.

Hauser, G. E. 1990. One-Dimensional Modeling of Summer Minimum Flow and Temperature in Chilhowee Tailwater. WR28-2-590-145. TVA Engineering Laboratory. Norris, Tennessee. January.

Hauser. G. E. 2003. River Modeling System v4: User Guide and Technical Reference. WR28-1-590-164. Tennessee Valley Authority River System Operations and Environment, Norris, Tennessee. October.

Hauser, G. E., and M. D. Bender. 1987. Temperature Modeling to Investigate the Use of Reservoir Releases to Create Trout Fishery Between Appalachia Dam and Powerhouse. WR28-1-15-102. Engineering Laboratory, TVA Division of Air and Water Resources. Norris, Tennessee. June.

Hauser, G. E., and W. G. Brock. 1993. Aerating weirs for environmental enhancement of hydropower tailwaters. North American Lake Management Society, Madison, Wisconsin.

Hauser, G. E., and D. I. Morris. 1995. High performance aerating weirs for dissolved oxygen improvement. Pages 1696-1705, in J. J. Cassidy, editor. ASCE Proceedings of the International Conference on Hydro Power: WaterPower '95, American Society of Civil Engineers, New York.

Hendricks, A. S. 1998. Labyrinth weir for dissolved oxygen improvement. Pages A62-A64 in S. H. Darling and H. H. Harper, editors. Proceedings of the Seventh Annual Southeast Lakes Management Conference. Orlando, Florida.

Herrmann, R. E., C. E. Warren, and P. Doudoroff. 1962. Influence of oxygen concentration on the growth of juvenile coho salmon. Transactions of the American Fisheries Society 91:155-167.

Hopping, P. P. March, T. Brice, and J. Cybularz. 1997. Update on development of auto-venting turbine technology. Pages 2020-2027 in J. J. Mahony, editor ASCE Proceedings of the International Conference on Hydro Power: WaterPower '97. American Society of Civil Engineers, New York.

Jarvis, D. E., C. Kempf, F. L. Putz, and G. A. Stoner. 1998. Using vents, low flows to enhance tailwater dissolved oxygen. Hydro Review 17(4): 72-73.

Lemons, J. W., M. C. Vorwerk, and J. H. Carroll. 1998. Determination of Richard B. Russell dissolved oxygen injection system efficiency utilizing automated remote monitoring technologies. Miscellaneous Paper W-98-1, Waterways Experiment Station, U. S. Army Corps of Engineers, Vicksburg, Mississippi.

Loginetics, Inc. 2004. Center Hill tailwater modeling for minimum flow evaluation. Report for U.S. Army Corps of Engineers, Nashville District, Nashville, Tennessee.

Meerbeek, J. R. 2005. Survival, growth, condition, and diet of stocked brown trout in five Tennessee tailwaters. Masters Thesis. Tennessee Technological University. May.

Mobley, M., W. Tyson, J. Webb, and G. Brock. 1995. Surface water pumps to improve dissolved oxygen content of hydropower releases. Pages 20-29 in J. J. Cassidy, editor. ASCE Proceedings of the International Conference on Hydro Power: WaterPower '95. American Society of Civil Engineers, New York. 
Price, R. E. 1988. Evaluation of release improvement techniques for J. Percy Priest Reservoir. Miscellaneous Paper HL-88-6. U.S. Army Corps of Engineers, Waterways Experiment Station, Vicksburg, Mississippi.

Sale, M. J., G.F. Cada, L.H. Chang, S. W. Christensen, S.F. Railsback, J.E. Francfort, B.N. Rinehart, and G.L. Sommers. 1991. Environmental mitigation at hydroelectric projects. Vol. 1. Current practices for instream flow needs, dissolved oxygen and fish passage. DOE/ID-10360, Idaho Falls, Idaho.

Shiao, M.C., and B. Yeager, 1997. Investigation of Velocity Distribution in the Douglas and Cherokee Tailwaters Under High Flow Conditions. WR28-1-590-167. TVA Engineering Laboratory. Norris, Tennessee. July.

Shiao, M. C., G. Hauser, B. Yeager, T. McDonough. 1993. Development and Testing of a Fish Bioenergetics Model for Tailwaters. TVA Engineering Services and Water Management Divisions. October.

Sigmon, J. C., G. D. Lewis, G. A. Snyder, and J. R. Beyer. 2000. Using hydro turbine aerating runner technology to enhance dissolved oxygen levels. HydroVision 2000. HCI Publications, Kansas City, Missouri.

Stewart, N. E., D. L. Shumway, and P. Doudoroff. 1967. Influence of oxygen concentration on the growth of juvenile largemouth bass. Journal of the Fisheries Research Board of Canada 24:475-494.

TWRA (Tennessee Wildlife Resources Agency). 2003. Management plan for the Center Hill tailwater trout fishery $-2004-2009$. Prepared by F. C. Fiss and D. W. Young. December.

Wahl, T. L., J. Miller, and D. Young. 1994. Testing turbine aeration for dissolved oxygen enhancement. ASCE Symposium on Fundamentals and Advancements in Hydraulic Measurements and Experimentation. American Society of Civil Engineers Symposium, Buffalo, New York, August 1-5, 1994. [online paper: http://www.usbr.gov/pmts/hydraulics_lab/pubs/pap/PAP-0650.pdf]

Whitworth, W. R. 1968. Effects of diurnal fluctuations of dissolved oxygen on the growth of brook trout. Journal of the Fisheries Research Board of Canada 25:579-584. 


\section{ORNL/TM-2005/188}

\section{INTERNAL DISTRIBUTION}

\author{
1-5. M. S. Bevelhimer \\ 6. G. F. Cada \\ 7. C. C. Coutant \\ 8. G. K. Jacobs \\ 9. M. J. Sale
}

\author{
10. R. B. Shelton \\ 11. B. T. Smith \\ 12-13. ESD Library \\ 14. ORNL Central Research Library \\ 15. ORNL Laboratory Records CRC
}

\section{EXTERNAL DISTRIBUTION}

16. Jim Ahlgrimm, EE-2B, US Department of Energy, Office of Wind \& Hydropower Technologies, Room 5H/072 FORS, 1000 Independence Ave., SW, Washington DC 20585

17. Paul Bernhardt, Reliant Energy, Inc., 225 Greenfield Parkway, Suite 201, Liverpool, NY 13088

18. Peggy Brookshier, U.S. Department of Energy, 1955 Fremont Ave. MS-1220, Idaho Falls, ID 83401-1220

19. Stephen Brown, Grant County PUD, P.O. Box 878 Ephrata, WA 98823

20. Tom Carlson, Pacific Northwest National Laboratory, 620 S.W. $5^{\text {th }}$ Avenue, Suite 810 , Portland, OR 97204

21. Peter Christensen, R2 Resource Consultants, 15250 NE $95^{\text {th }}$ Street, Redmond, WA 98052

22. Bill Christman, Chelan County PUD, 327 North Wenatchee Ave., P.O. Box 1231, Wenatchee, WA 98801

23. Ron Corso, Mead \& Hunt, Inc., 904 Farley Court, S.E., Vienna, VA 22180-5916

24. Dennis D. Dauble, Pacific Northwest National Laboratory, Battelle Boulevard, P.O. 999, Richland, WA 99352

25. Doug Dixon, EPRI, 7905 Berkeley Drive, Gloucester Point, VA 23062

26. Steve Doret, Stone \& Webster Consultants, Inc., One Bowdoin Square, Boston, MA 02114

27. Laurie L. Ebner, U.S. Army Corps of Engineers, P.O. Box 2946, Portland, OR 97208-2946

28. John W. Ferguson, National Marine Fisheries Service, Northwest Fisheries Center, 2725 Montlake Boulevard, East Seattle, WA 98112

29-30. Stanley Calvert, EE-2B, US Department of Energy, Office of Wind \& Hydropower Technologies, Room 5H/072 FORS, 1000 Independence Ave., SW, Washington DC 20585

31. Gary Hauser, Loginetics, P.O. Box 18274, Knoxville, TN 37928

32. Scott Hendricks, Georgia Power Company, Environmental Laboratory, 5131 Maner Road, Smyrna, GA 30080

33. Jennifer Hill, Federal Energy Regulatory Commission, 888 First Street, N.E., Washington, DC 20426

34. Mike Langeslay, U.S. Army Corps of Engineers, P.O. Box 2946, Portland, OR 97208-2946

35. Charles R. Liston, Consultant, 168 Ralston Road, Bedford, KY 40006

36. Edward Meyer, National Marine Fisheries Service, 525 N.E. Oregon St., Suite 500, Portland, OR 97232-2737

37. Lawrence B. Moore, Southern Services Company, 42 Inverness Center Parkway, Birmingham, AL 35242

38. Thomas R Murphy, Federal Hydro Projects, Bonneville Power Administration, PGF/6th Floor, P.O. Box 3621, Portland, OR 97208-3621 
39. Roger Mann, Recon, 1677 Colusa Avenue, Davis, CA 95616

40. Robert Sneed, USACE Nashville District, Nashville, TN

41. Phillip Bettoli, Tennessee Tech University, Box 5114, Cookeville, TN 38505 